\title{
Boolean-Based Surface Procedure for the External Heat Transfer Analysis of Dams during Construction
}

\author{
Yu Hu, Zheng Zuo, Qingbin Li, and Yunling Duan \\ State Key Laboratory of Hydroscience and Engineering, Department of Hydraulic Engineering, \\ Tsinghua University, Beijing 100084, China
}

Correspondence should be addressed to Zheng Zuo; zuozheng.thu@gmail.com

Received 19 July 2013; Accepted 4 September 2013

Academic Editor: Song Cen

Copyright (C) $2013 \mathrm{Yu} \mathrm{Hu}$ et al. This is an open access article distributed under the Creative Commons Attribution License, which permits unrestricted use, distribution, and reproduction in any medium, provided the original work is properly cited.

The external heat transfer of dams during construction is complex because such transfer is location specific and time varying. An external thermal model is developed in this paper. Five types of external heat flux are considered in the mathematical model: airside convection, electromagnetic radiation, absorbed solar input, water-side convection, and surface insulation effect. A method for extracting and classifying the external surfaces of dams on the basis of Boolean operations is proposed. Heat transfer conditions can be automatically set up for each step according to the proposed method, and the method can be used as a preprocessing facility for finite element analysis. A $285 \mathrm{~m}$ high arch dam in Southwest China is examined as a study case. The model is implemented and found to correctly identify different types of external surfaces. Simulation result agrees well with the monitored temperatures.

\section{Introduction}

Concrete is the most widely used building material in the world. Rough statistics [1] show that over two billion ton quantities of concrete are produced all over the world per year. Temperature plays an important role in the construction of concrete structures [2]. Considerable heat is released during the hydration reaction of young-age concrete. This heat results in temperature gradients near the structure surface because of external heat transfer under varying atmospheric conditions. A large volume of concrete increases the gradients and increases the risk of thermal-stress-induced cracks [3], thereby decreasing the long-term strength and durability of concrete. Thus, developing an appropriate thermal analysis method for concrete, particularly for mega structures (e.g., concrete dams), during the construction phase is essential and necessary.

A dam comprises an extremely large amount of concrete and is referred to as a typical case of massive concrete. To complete this colossal project, the structure must be divided into numerous blocks cast at different times. The entire construction usually requires a number of years to complete, which means that the climate condition changes with seasonal variation during the construction phase. A good example would be the construction of the famous Three Gorges Dam, which took a total of 14 years to complete 27.2 million cubic meters of concrete [4].

The boundary conditions should be consistent with the practical situation to ensure the accuracy of simulating the heat transfer problem. However, the setup work poses difficulty in simulating large and complex structures such as concrete dams. On one hand, the dam is bounded by a group of surfaces, which are subjected to various external thermal conditions. On the other hand, the dam constantly grows with the gradually changing boundary surfaces. Therefore, external thermal conditions are location specific and time varying, which makes the selection and setup of the boundary conditions complex. The surfaces of different steps are manually chosen in conventional thermal simulations, which is a tedious and time-consuming task that does not guarantee absolute accuracy.

A number of experimental and numerical studies on the external heat transfer problem of concrete were conducted. For instance, Demir [5] investigated the natural 
convection temperature/velocity field around a horizontal concrete cylinder that is heated with a heat source. Lee et al. [6] conducted an experiment to investigate the convective heat transfer coefficient during the hydration process. $G$. F. Jones and R. W. Jones [7] studied a heat transfer problem for an insulated and reinforced concrete wall, in which the surface boundary is solved by using Newton's cooling law. However, these studies mainly focused on stable laboratory test conditions where the external heat transfer boundary condition is relatively simple.

Much effort was given to study the external heat transfer of dams. Léger and Seydou [8] and Léger and Leclerc [9] investigated the $1 \mathrm{D} / 2 \mathrm{D}$ temperature field of some dams during the operating phase. Sheibany and Ghaemian [10] intensively studied the environmental effect of heat transfer in arch dam engineering but failed to consider the surface insulation effect. In another study, Jin et al. [11] investigated the solar effect on exposed dam surfaces during the operating phase. However, the objects of these studies were dams that had already been built; that is, the dams were already under the postconstruction or operation phase, where the situation of the external surface boundary regions barely changes.

The finite element (FE) method is widely used to simulate the thermal problem of dams during the construction phase. Numerous relevant studies address the FE method [2, 12-21]. Cervera et al. [12] translated a 3D thermal problem into a $1 \mathrm{D} / 2 \mathrm{D} \mathrm{FE}$ analysis problem by simplifying the longitudinal direction. Wu and Luna [2] and Luna and Wu [15] studied the numerical implementation of the thermal stress problem in roller-compacted concrete (RCC) dams without considering solar and electromagnetic radiation. Saetta et al. [16] proposed the constituting factors of the external thermal flux. However, they did not discuss exact estimation methods. Noorzaei and Bayagoob $[18,19]$ simulated RCC dams that are under construction to study wind and solar effects. However, the solar input in their study was simplified to a constant.

The numerical thermal simulation of dams had been studied, but the setup problem of the external boundary conditions at each step was not technically discussed. Limited studies focus on the preliminary procedure of external surfaces for the external heat transfer of dams. Therefore, this study presents a method for the automatic setup of external heat transfer boundaries during the analysis of the entire construction phase. The external heat transfer of dams is classified, and the basic mathematical model is established. Boolean-based algorithms are proposed to extract different types of external surfaces and to set appropriate heat transfer conditions. A super-high arch dam is examined as a study case by using the developed program to test the automatic method in practical engineering applications.

\section{Mathematical Model}

The governing equation of $3 \mathrm{D}$ unsteady heat transfer can be derived from the energy conservation principle and the Fourier law of heat conduction, which is written as follows:

$$
\rho C_{p} \frac{\partial T}{\partial \tau}=\left(\lambda_{x} \frac{\partial^{2} T}{\partial x^{2}}+\lambda_{y} \frac{\partial^{2} T}{\partial y^{2}}+\lambda_{z} \frac{\partial^{2} T}{\partial z^{2}}\right)+f
$$

where $T$ is the temperature; $\lambda$ is the thermal conductivity, which is always considered isotropic in concrete material; that is, $\lambda=\lambda_{x}=\lambda_{y}=\lambda_{z} ; f$ is the internal heat source produced per volume, homogeneously distributed over the concrete. $f$ generally consists of two main parts: hydration heat generation and the cooling effect of embedded coolpipes, which was investigated in our previous work $[14,17,20]$.

Massive concrete has complex boundary conditions during the construction phase. The external heat transfer of the boundary surfaces can generally be expressed as

$$
q=\lambda \frac{\partial T}{\partial n}=f\left(q_{c}, q_{r}, q_{a}, q_{w}, q_{p}\right)
$$

where $n$ is the normal direction of the external surfaces and $q$ is the external heat flux, which is a combination of five components. These components are discussed in detail in this section. Various combinations are applied in different surface areas to simulate a dam during construction. The rule of the combination setup is presented in detail in Section 4 .

2.1. Air-Side Convection. Heat convection occurs upon exposed concrete surfaces because of the bulk motion of air fluids that carry and disperse the heat [22]. The airside convective flux $q_{c}$ is proportional to the temperature difference between the concrete and the surrounding air. Heat convection can be given by using Newton's law of cooling or by using the Robin boundary condition:

$$
q_{c}=h_{c}\left(T-T_{a}\right),
$$

where $T_{a}$ denotes the ambient temperature and $h_{c}$ denotes the convective coefficient, which is considered constant in some previous studies on dams $[2,11,14]$. However, the convective coefficient is actually affected by numerous factors, among which wind speed was highlighted in recent studies as the major factor $[23,24]$. The thermal simulation of dams should consider this wind effect because dams are commonly built in canyons where wind is naturally strong. NusseltJürges correlation [23], a well-established form of convective coefficient that considers wind speed, is used in this paper and can be defined as

$$
h_{c}=5.678\left\{a+b\left[\left(\frac{294.26}{T_{a}^{[K]}}\right) \frac{V_{w}}{0.3048}\right]^{m}\right\},
$$

where $V_{w}$ is the wind speed; $a, b$, and $m$ are the parameters to be decided based on the applied condition; $T_{a}^{[K]}$ is notably the degree Kelvin of ambient temperature. The following equation gives the conversion formula based on degree Celsius:

$$
[K]=\left[{ }^{\circ} \mathrm{C}\right]+273.15
$$

Air temperature always varies and hardly remains constant even throughout a single day. In this work, the $T_{a}$ of each step is used as the mean temperature over the increment of time. Constantly recording the ambient temperature is impractical; thus, we use the daily mean temperature to represent the entire day for convenience. We can employ 


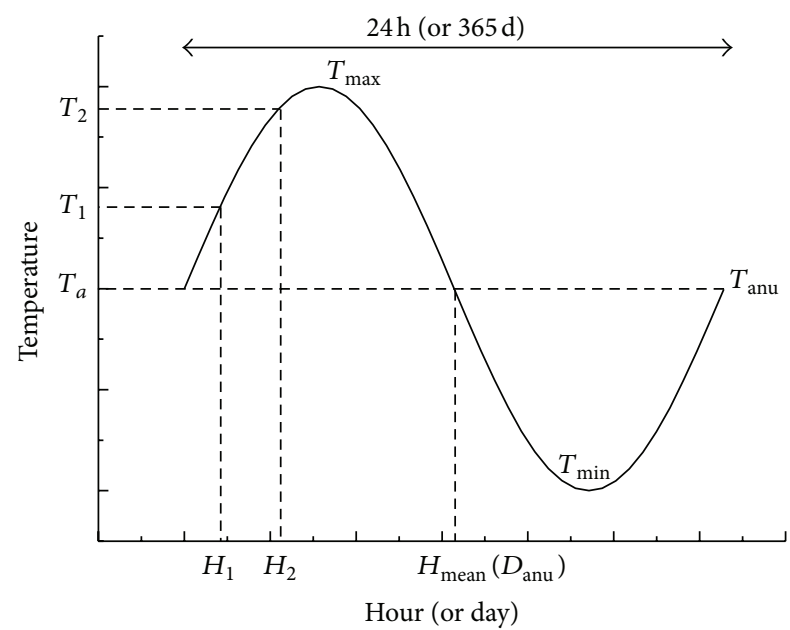

FIGURE 1: Ambient temperature sinusoid curve for one day (or one year).

a sinusoid function [25] curve with a period of $24 \mathrm{~h}$ for typical temperature history (see Figure 1). The mean daily temperature can be fit with two measured temperatures $T_{1}$ and $T_{2}$ at times $H_{1}$ and $H_{1}$ by using the following equation:

$$
T_{a}=\frac{T_{1}-\left(T_{2}-T_{1}\right) \sin \left[\left(H_{1}-H_{\text {Mean }}\right) \pi / 12\right]}{\sin \left[\left(H_{2}-H_{\text {Mean }}\right) \pi / 12\right]-\sin \left[\left(H_{1}-H_{\text {Mean }}\right) \pi / 12\right]},
$$

where $H_{\text {Mean }}$ is the middle time between the peak and valley. When the record time is at the middle time such as $\tau_{1}=$ $\tau_{\text {mean }}$, the temperature measured at that time can be directly considered the mean temperature; that is, $T_{a}=T_{1}$.

Unfortunately, recording or accessing detailed local weather data in some engineering projects is difficult and cannot be guaranteed even though only one temperature measurement per day is taken. That implies that daily temperatures cannot be determined from (6). We can apply the following sinusoidal curve to approximate $T_{a}$ over the entire year:

$$
T_{a}(D)=0.5\left(T_{\text {Max }}-T_{\text {Min }}\right) \sin \left[\frac{2 \pi\left(D-D_{\text {Anu }}\right)}{365}\right]+T_{\text {Aun }},
$$

where $D$ denotes the day of the year (e.g., 1 for January 1 st and 32 for February 1st).

2.2. Exposed Radiation to Environment. Electromagnetic energy is constantly emitted by concrete through exposed surfaces and can be calculated by using the Stefan-Boltzmann law:

$$
q_{r}=F_{r} \sigma\left[\left(T^{[K]}\right)^{4}-\left(T_{a}^{[K]}\right)^{4}\right],
$$

where $F_{r}$ is the emissivity of the surface and $\sigma=5.670373 \times$ $10^{-8} \mathrm{~W} \mathrm{~m}^{-2} \mathrm{~K}^{-4}$, which is referred to as the Stefan-Boltzmann constant [26]. The temperatures applied in (8) should notably be used in degree Kelvin.
2.3. Absorbed Radiation from the Sun. Solar radiation was not considered in numerous thermal studies on dams $[2,14,15]$. A recent work [11] showed that irradiation has a great thermal effect on the exposed surfaces of a dam. Proper calculation of the absorbed solar radiation of the structure surface is complex because of considerations such as the sun's position, environmental factors, and surface conditions.

The revolution orbit and rotation circle of the earth are not on the same plane because the equatorial plane tilts at an angle of $23.45^{\circ}$ to the orbital plane. Solar declination $\delta$, which is defined as the angle between the earth-sun line and the equatorial plane, consequently varies from $0^{\circ}$ to $23.45^{\circ}$ during one period of revolution (see Figure 2). The daily declination is obtained through approximation throughout a year as

$$
\delta=23.45^{\circ} \sin \left(360^{\circ} \frac{D+284}{365}\right)
$$

where $D$ is the day of year. The equation shows that if $81<$ $D<263.5$ then $\delta>0$, which is the time when the earth-sun line crosses the Northern Hemisphere, namely, the summer time for the Northern Hemisphere.

Figures 2 and 3 show the position map of the sun and the structure surface of the earth. The relation among these angles through a $3 \mathrm{D}$ geometry deduction can be written as

$$
\begin{gathered}
\sin \beta=\cos L \cos \delta \cos H+\sin L \sin \delta, \\
\sin \phi=\frac{\sin H \cos \delta}{\cos \beta}, \\
\cos \phi=\frac{\cos H \cos \delta \sin L-\sin \delta \cos L}{\cos \beta}, \\
\gamma=\phi-\psi, \\
\cos \phi=\cos \beta \cos \gamma \sin \mu+\sin \beta \cos \mu,
\end{gathered}
$$

where $H$ is the hour angle (the detailed calculation of this variable is tallied in the appendix); $L$ is the latitude value (in degrees: positive for the northern site and negative for the southern site); $\mu$ is the inclination angle of the structure surface; $\theta$ is the angle of incidence, which is the angle between the earth-sun line and the line normal to the surface; $\psi$ is the surface azimuth, which is defined as the angular displacement from the south direction to the normal direction of the structure surface on the horizontal plane; $\beta$ is the solar altitude angle, which represents the angle between the horizontal plane and the emanating line from the sun; $\gamma$ is the surface-solar azimuth angle; $\phi$ is the solar azimuth angle.

We can obtain the exact values of $L, H, \delta, \psi$, and $\mu$ for a specific time on a specific location on earth. Then, $\beta$ can be calculated by (10), $\phi$ can be found by (11) and (12), and $\theta$ is determined by (14). So far, all the solar angles involved in the irradiation computation are obtained. When $H=0, \beta$ notably reaches the daily maximum angle of $\pi / 2-|L-\delta|$, which is the moment called the solar noon.

When the sun's position and solar angles are determined as described, we can calculate the total solar energy input 


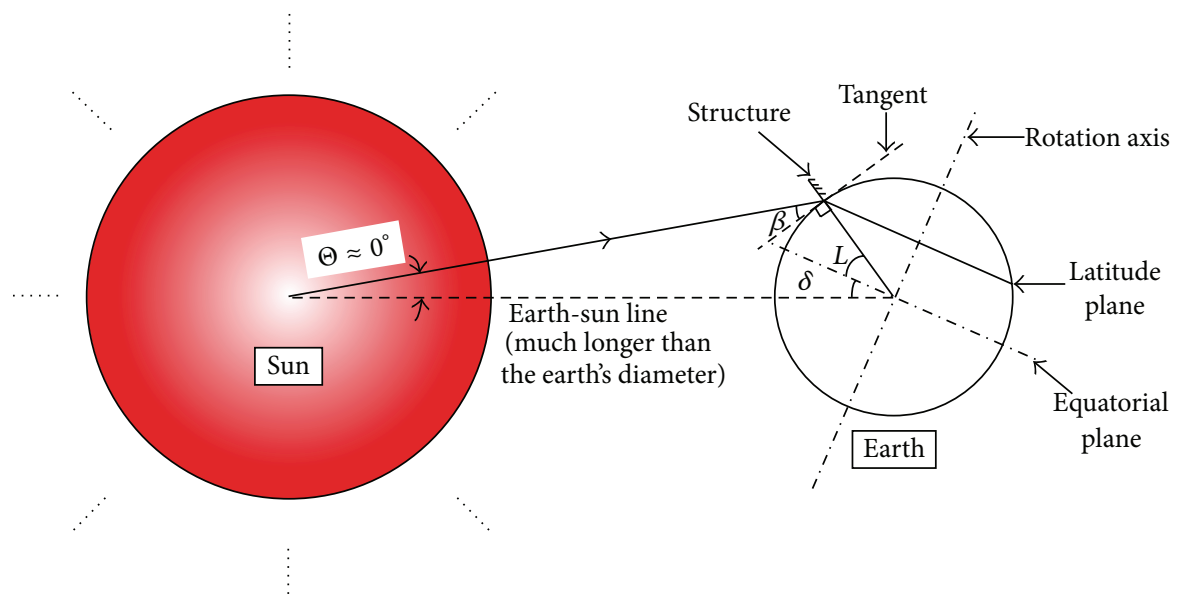

Figure 2: Positions of the Sun and the Earth (this figure shows a winter time for the north because the Earth-Sun line crosses the Southern Hemisphere).

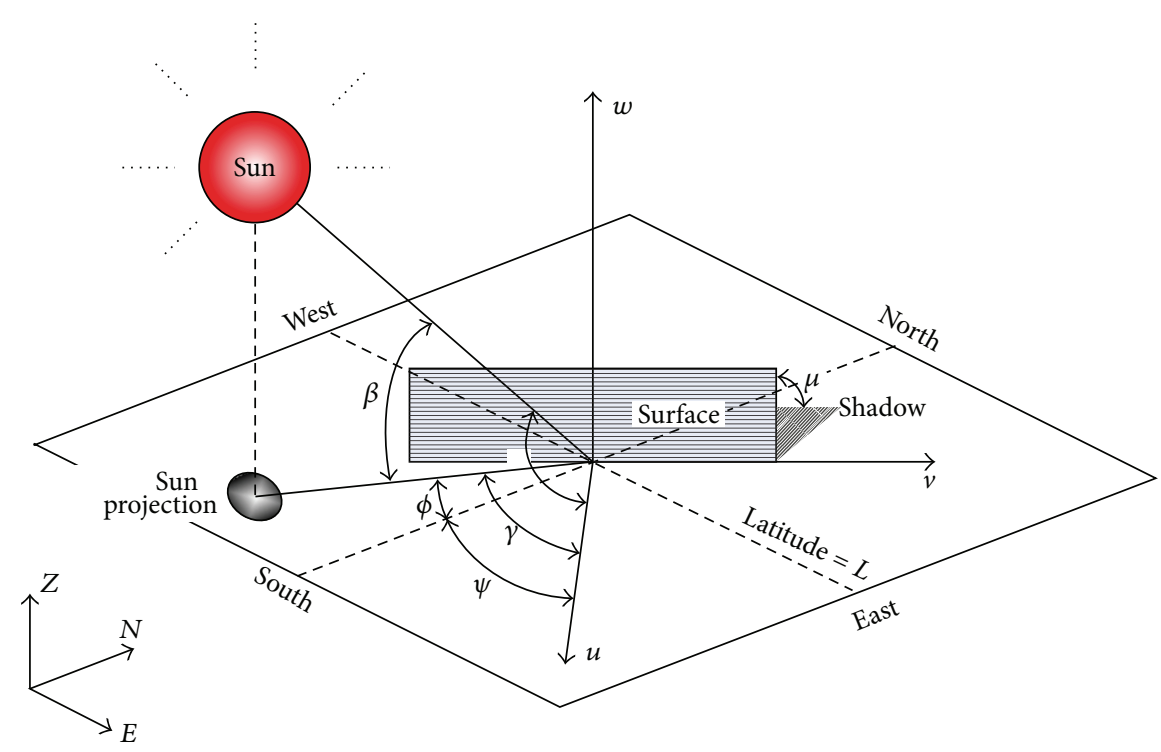

FIGURE 3: Solar angles involved for a structure surface.

that strikes the structure surface. This energy input can be measured by using three components:

$$
E_{\text {Sun }}=Y_{\text {Beam }} E_{\text {Beam }}+Y_{\text {Diff }} E_{\text {Diff }}+E_{\text {Refl }} \text {, }
$$

where $E_{\text {Beam }}, E_{\text {Diff, }}$, and $E_{\text {Refl }}$ represent the beam (direct), diffuse, and ground reflector components of solar radiation from the sky dome and $Y_{\text {Beam }}$ and $Y_{\text {Diff }}$ represent the irradiation coefficient, considering the surface angle. These components can be obtained through mathematical and geometry relations with the extraterrestrial solar radiation from a clear-sky model proposed by ASHRAE [27]:

$$
\begin{aligned}
& E_{\text {Beam }} \\
& =E_{0} \exp \left(-\eta_{\text {Beam }} m^{\left.1.219-0.043 \eta_{\text {Beam }}-0.151 \eta_{\text {Diff }}-0.204 \eta_{\text {Beam }} \eta_{\text {Dif }}\right),}\right. \\
& Y_{\text {Beam }}=\max (\cos \theta, 0),
\end{aligned}
$$

$$
\begin{gathered}
E_{\text {Diff }} \\
=E_{0} \exp \left(-\eta_{\text {Diff }} m^{0.202+0.852 \eta_{\text {Beam }}-0.007 \eta_{\text {Diff }}-0.357 \eta_{\text {Beam }} \eta_{\text {Diff }}}\right) \\
Y_{\text {Diff }}=[\max (0.45,0.55+0.437 \cos \beta \cos \gamma \\
\left.\left.\quad+0.313 \cos ^{2} \beta+\cos ^{2} \gamma\right)\right] \sin \mu \cos \mu \\
E_{\text {Refl }}=\frac{1-\cos \mu}{2} g\left(E_{\text {Beam }} \sin \beta+E_{\text {Diff }}\right)
\end{gathered}
$$

where $E_{0}$ is the extraterrestrial solar radiant flux, $m$ is the relative air mass, $\eta$ is the parameter that represents optical depths, and $g$ is the ground reflectance of the foreground. These four parameters can be investigated as described in the following paragraphs. 
The extraterrestrial solar radiant flux $E_{0}$ varies throughout the year owing to the slightly elliptical orbit path, which can be given by

$$
E_{0}=E_{\mathrm{sc}}\left\{1+0.033 \cos \left[360^{\circ} \frac{(D-3)}{365}\right]\right\}
$$

where $E_{\mathrm{sc}}=1367 \mathrm{~W} / \mathrm{m}^{2}$ and is referred to as the solar constant [28].

The relative air mass $m$ represents the ratio of the actual air mass to the air mass with the sun shining directly overhead. $m$ can be considered a function of the solar altitude angle $\beta$ [29] as follows:

$$
m=\frac{1}{\sin \beta+0.50572(6.07995+\beta)^{-1.6364}} .
$$

The ground reflectance $g$ depends on the reflectance capability of the foreground near the site, ranging from 0 to 1. Several reflectance parameters of typical landforms were listed in a previous study [30], where water and dry ground were 0.07 and 0.20 , respectively.

The parameters that represent the optical depths $\eta_{\text {Beam }}$ and $\eta_{\text {Diff }}$ are location specific, and the data from 11,124 stations worldwide can be found in the ASHRAE handbook [27].

In terms of reaching solar energy $E_{\text {Sun }}$, the structure surface would absorb a part of this energy while reflecting the rest. The absorbed energy can then yield a correlation expression as

$$
q_{a}=\zeta E_{\mathrm{Sun}}
$$

where the scale factor $\zeta$ is the absorptivity of the exposed surface.

Solar radiation input occurs only during daytime with a clear sky. $q_{a}$ is small during night and rainy days and can be neglected. In engineering applications, the daily energy can be summed up on the basis of the hourly $E_{\text {Sun }}$ value:

$$
q_{a}(D)=\zeta \sum_{H=H_{\text {Rise }}}^{H_{\text {Set }}-H_{\text {Rise }}} E_{\text {Sun }}(H)=\zeta \overline{E_{\text {Sun }}}\left(H_{\text {Set }}-H_{\text {Rise }}\right) \text {, }
$$

where $H_{\text {Rise }}$ and $H_{\text {Set }}$ denote the sunrise and sunset hours, respectively, and $\overline{E_{\text {Sun }}}$ denotes the time average value of $E_{\text {Sun }}$ during daytime.

2.4. Water-Side Convection. Several dams begin to fill the reservoir during the construction phase to improve the performance of power production, which results in the concrete exchanging heat with the reservoir through the waterside surface below the reservoir level. This phenomenon is considered a convection boundary with liquid fluid, which can also be described in Newton's law of cooling:

$$
q_{w}=h_{w}\left(T-T_{w}\right)
$$

where $T_{w}$ denotes the water temperature and $h_{w}$ denotes the convection coefficient between the concrete and water. Coefficient $h_{w}$ is relatively large for water-side convection unlike that for air-side convection. The water-side convection coefficient is 20 times to 1000 times that of the air-side convection $[31,32]$. In this situation, the boundary can be directly dealt as a Dirichlet boundary condition (first-type boundary condition):

$$
T=T_{w}
$$

In engineering applications, $T_{w}$ can be obtained by monitoring the water temperature or through the empirical prediction method $[33,34]$.

2.5. Surface Protection. The concrete surface may be covered with insulation protections during construction to prevent thermal cracks induced by atmospheric temperature shock. Materials with high thermal resistances, such as cotton quilts, polystyrene foam plastic (PFP) [35] boards, and sprayed polyurethane, are ideal options for protection in engineering applications. Figure 4 shows two typical thermal protections used in dams. Tiling the cotton quilt on horizontal surfaces, such as the top faces of new-cast lifts, is convenient. And polystyrene foam boards are suitable for pasting clung to the nonhorizontal surfaces. We can consider the boundary condition as a composite wall comprising miscellaneous materials in a series. Similar to the air-side convection, we can apply the following Robin boundary condition:

$$
q_{p}=h_{p}\left(T-T_{a}\right),
$$

where $h_{p}$ denotes the equivalent convection coefficient of the protection series and is given as the reciprocal of the sum of thermal resistances:

$$
h_{p}=\frac{1}{1 / h_{c}+\sum b_{p} / \lambda_{p}},
$$

where $h_{c}$ denotes the nonprotective convective coefficient in a nonwind condition $\left(V_{w}=0\right.$ in (4)), $b_{p}$ denotes the width of each protection, and $\lambda_{p}$ denotes the thermal conduction coefficient of each insulation layer.

\section{Finite Element Methods}

Solving (1) through analytical methods with the aforementioned geometrically complex dam structures and various boundary conditions is impractical. The FE method, which is the most widely applied numerical tool in engineering fields, is chosen as the numerical approach to solve the heat transfer problem of the dam under construction in this study.

The 3D space $V$ can be subdivided into numerous elements. Let $T^{e}$ be the temperature of an arbitrary location within an element, which can be interpolated as a function of the nodal temperatures on this element mesh:

$$
T^{e}=[N]\{T\}^{e},
$$

where $\{T\}^{e}$ denotes the nodal temperature arrays and $[N]$ denotes the interpolation function matrix. We can also transpose (29) into (1). The classic FE formulation can be formed as

$$
[C]\left\{\frac{\partial T}{\partial \tau}\right\}+[K]\{T\}=\{Q\},
$$




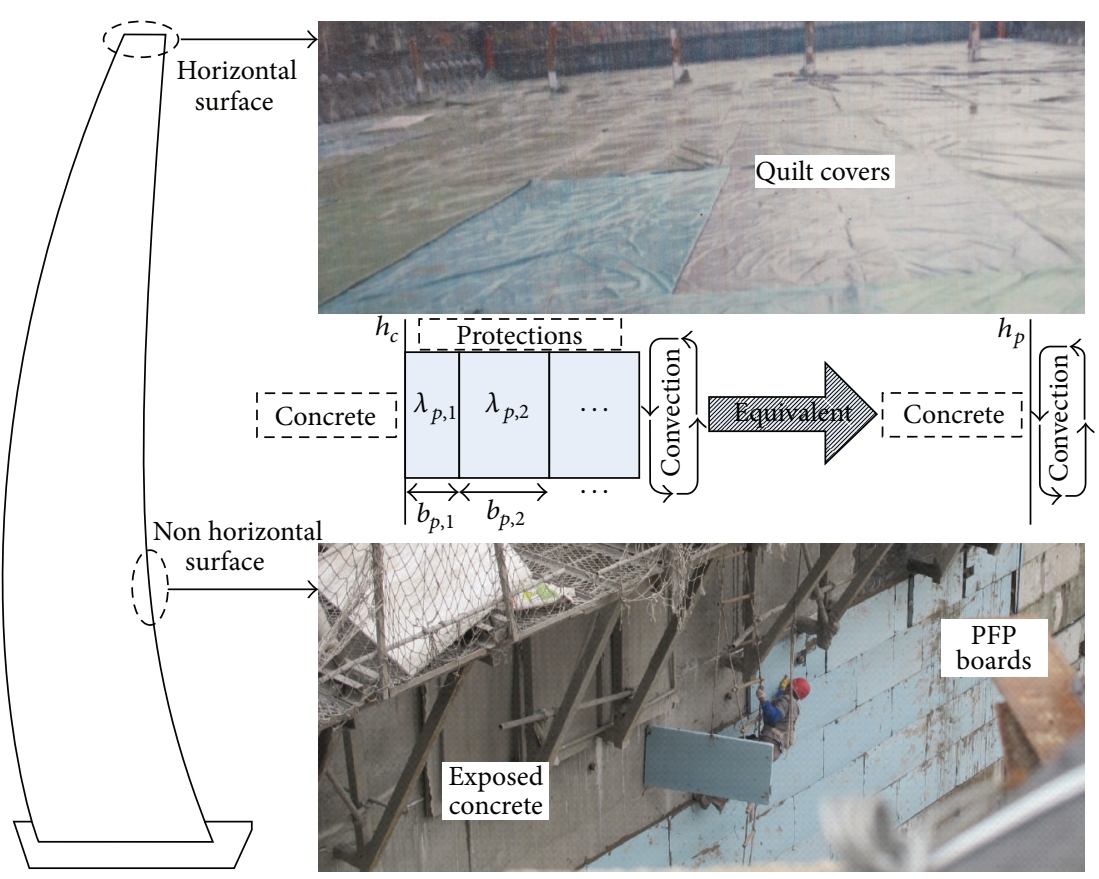

FIGURE 4: Surface protection and its equivalent model.

where $[C]$ and $[K]$ denote the heat capacity and thermal conductivity matrices, respectively and $\{Q\}$ denotes the heat flux vector:

$$
\begin{gathered}
{[C]=\rho C_{p} \int_{V}[N]^{T}[N] d V,} \\
{[K]=\rho C_{p} \int_{V}[M]^{T} \lambda[M] d V,} \\
\{Q\}=\int_{V}[N]^{T} f d V,
\end{gathered}
$$

where $[M]$ is the derived form of $[N]$.

Given the boundary conditions mentioned in (2), $\{Q\}$ can be rewritten as

$$
\begin{aligned}
\{Q\}= & \int_{V}[N]^{T} f d V+\int_{\Gamma_{c}}[N]^{T} q_{c} d \Gamma_{c}+\int_{\Gamma_{r}}[N]^{T} q_{r} d \Gamma_{r} \\
& +\int_{\Gamma_{a}}[N]^{T} q_{a} d \Gamma_{a}+\int_{\Gamma_{w}}[N]^{T} q_{w} d \Gamma_{w}+\int_{\Gamma_{p}}[N]^{T} q_{p} d \Gamma_{p},
\end{aligned}
$$

where $\Gamma$ represents the external surface regions, which have various types. The method of determining the different types of surface regions at different times is proposed in Section 4 .

Equation (30) yields the following expression with the help of the backward difference scheme through the discretization of the time dimension:

$$
\left(\frac{1}{\Delta \tau}[C]+[K]\right)\{T\}_{\text {inc }}=\{Q\}_{\text {inc }}+\frac{1}{\Delta \tau}[C]\{T\}_{\text {inc }-1},
$$

where $\Delta \tau$ denotes the increment time and the subscript inc is the time increment. The initial condition and thermal boundary conditions are known. The temperature field of any time can be deduced increment by increment.

\section{Boolean-Based Surface Procedure}

The external heat transfer conditions during the construction phase of a large dam are complex. For a proper FE analysis of a dam under construction, the casting of a new lift means activating the lift elements, which changes the external surface regions. In some large projects, the dam is composed of thousands of lifts, which makes the manual selection of different types of surfaces at each step impractical. Therefore, an automatic surface extracting and taxonomy method based on Boolean operations is presented in this study.

4.1. Boolean Operations. Boolean operations are a group of symbolic computation rules used to operate polygons. Three basic operations are always conducted as illustrated in Figure 5: intersection, union, and difference. In the programming of a Boolean-based operation between two surface sets (e.g., $M$ and $N$ ), two labels $m$ and $n$ are attached on each surface element. If the element belongs to the set $M, m=1$; otherwise, $m=0$. Similarly, $n=1$ refers to the elements in the internal area of $N$. Therefore, the rules of the Boolean-based operation can be defined as follows.

(i) Intersection: it is denoted as $M \wedge N$, which generates the set of elements located in the area where $M$ and $N$ overlap. This rule means that the sets are the elements with $m+n=2$.

(ii) Union: it is denoted as $M \vee N$, which generates the set of overall elements, which is a member of $M, N$, or both. This rule means that the sets are the elements with $m+n \geq 1$.

(iii) Difference: it is denoted as $M-N$, which generates the set of elements located where $M$ remains when $N$ 
(1) Read surface sets already been defined, $S_{1}, S_{2}, S_{3}$ and $S_{4}$, according to Section 4.2.

(2) Detect outlet hole surfaces in the dam body, and store them as $S_{5}$, according to Algorithm 3.

(3) Detect joint surfaces between adjacent monoliths, and store them as $S_{6}$, according to Algorithm 3.

(4) Detect foundation surfaces between dam and rock, and store them as $S_{-}$rock, according to Algorithm 3.

(5) Kill all the dam elements. // the elements whose lift ID $>0$.

(6) for $i=1,2, \ldots$, steps do

(7) Activate the lift cast at this step. $\quad / /$ the elements whose lift_ID $=i$.

(8) Recognize external surfaces of activated elements, store them as $S_{-}$all according to Algorithm 2.

(9) Look for the element surfaces with lift_ID $=i$ from $S_{-}$all, and note them as $S_{-}$lift.

(10) $\quad$ S_rock $=S \_$rock $\wedge$ S_all.

(11) $\quad S_{-}$up $=\left(S_{-}\right.$lift $\left.\wedge S_{3}\right) \vee S_{-}$up .

end loop $i$.

$S_{\_}$down $=\left(S_{-}\right.$lift $\left.\wedge S_{4}\right) \vee S_{-}$down

$S_{-j o i n t}=S_{6} \wedge S_{-}$all.

S_hole $=S_{5} \wedge S_{-}$all .

$S \_t o p=S \_$all $-S_{\_}$up $-S_{\_}$down $-S_{-}$joint $-S \_$hole .

Set boundary conditions according to Table 2

Seek the highest elevation $z$ of nodes in the latest cast lift, which is noted as $z_{-} h$.

$z \_$mono $\left[\right.$mono $\left.\_I D[i]\right]=\mathrm{z} \_h$. // change the top elevation of the new-rise monolith.

for $j=1,2, \ldots$, incs $[i]$. // increments of this step

end loop $j$.

Finite element solver.

Algorithm 1: Boolean-based surface procedure.

TABLE 1: Predefined variables.

\begin{tabular}{|c|c|c|}
\hline Variables & Dependence & Note \\
\hline lift_ID & Element dependent & $\begin{array}{l}\text { The label of the casting sequence and lift_ID }=0 \text { represent the nonconcrete } \\
\text { elements (i.e., rock base). }\end{array}$ \\
\hline mono_ID & Lift dependent & $\begin{array}{l}\text { The variable represents the monolith to which the lift belongs, and mono ID } \\
{[0]=0 .}\end{array}$ \\
\hline$z \_$mono & Monolith dependent & $\begin{array}{l}\text { The variable represents the highest elevation of each monolith during } \\
\text { construction, where all variables are initially set as } 0 .\end{array}$ \\
\hline
\end{tabular}

is substracted. This rule means that the sets are the elements with $m-n=1$. Similarly, $n-m=1$ yields the result of the $N-M$ operation.

4.2. Preliminary Defining Surfaces. Four simple preliminary surface groups should be identified to obtain precisely different types of external surfaces in the simulation. Figure 6 shows the preliminary surface groups of a typical arch dam layout.

(i) Model-side surfaces: the in-rock boundary surfaces of the model should be identified and noted as $S_{1}$.

(ii) Dam-top surfaces: the top surfaces of the dam body should be identified and noted as $S_{2}$, and usually those surfaces are on the same elevation.

(iii) Upstream surfaces: the upstream surfaces of the dam should be identified and noted as $S_{3}$.

(iv) Downstream surfaces: the downstream surfaces of the dam should be identified and noted as $S_{4}$.

Death/rebirth technology is used to simulate the construction process in FE analysis. The entire analysis is divided into numerous steps on the basis of the casting-time plan. The lift elements are activated at the beginning of each step. A lift $I D$ variable is created for each element to store the lift casting sequence. Two additional arrays are used to represent the space relations, as shown in Table 1.

4.3. Surface Procedure and FEM Implementation. We are now ready to present the surface extraction and taxonomy procedures based on Boolean operations. First we set a nomenclature rule of the surface group identification. (1) Postfix including integer numbers are the surfaces remain the same during the analysis, or we can name them as static surfaces, like $S_{1}, S_{2}$, and so forth. (2) Postfix including characters are the surfaces change during the analysis, or we can name them as dynamic surfaces, like $S_{-}$up, $S_{-}$down, and so forth. The pseudo-code description of the procedure can be summarized by the following algorithm.

Various types of external heat transfer occur on different surfaces during construction. More than one type of heat transfer may co-exist on one surface. The surfaces stored in Algorithm 1 are an efficient taxonomy method for each step. We can set the boundary condition as summarized in Table 2. 


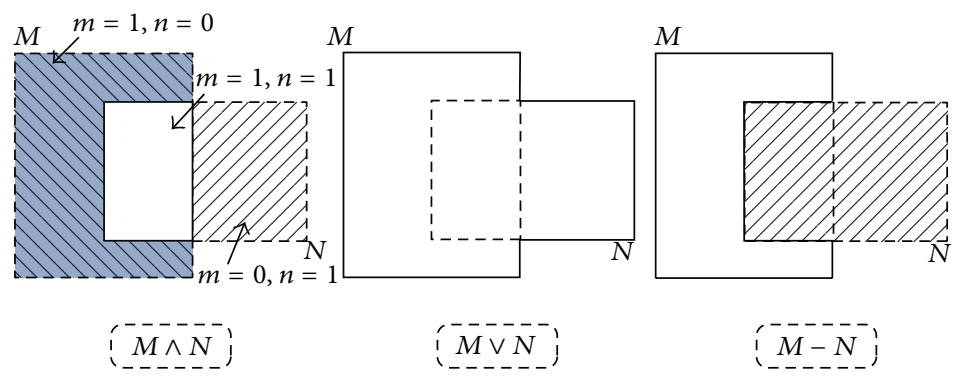

Figure 5: Surface Boolean operations.

TABLE 2: External surface taxonomies for boundary conditions setup.

\begin{tabular}{|c|c|c|}
\hline Surface region & & Combination of boundary conditions \\
\hline In-rock boundary surfaces & $S_{1}$ & $\begin{array}{l}q(\tau)=0\left(z>z_{g}\right) \\
T(\tau)=T_{g}\left(z \leq z_{g}\right)\end{array}$ \\
\hline Rock-exposed surfaces & S_rock & $q(\tau)=q_{c}+q_{r}+q_{a}$ \\
\hline Upstream surfaces & $S_{-} u p$ & $q(\tau)= \begin{cases}q_{c}+q_{r}+q_{a} & \left(z>z_{\text {up }}, p(\tau)=0\right) \\
q_{p} & \left(z>z_{\text {up }}, p(\tau)=1\right) \\
q_{w} & \left(z \leq z_{\text {up }}\right)\end{cases}$ \\
\hline Downstream surfaces & S_down & $q(\tau)= \begin{cases}q_{c}+q_{r}+q_{a} & \left(z>z_{\text {down }}, p(\tau)=0\right) \\
q_{p} & \left(z>z_{\text {down }}, p(\tau)=1\right) \\
q_{w} & \left(z \leq z_{\text {down }}\right)\end{cases}$ \\
\hline Joint surfaces & S_joint & $q(\tau)= \begin{cases}q_{c}+q_{r}+q_{a} & (p(\tau)=0) \\
q_{w} & (p(\tau)=1)\end{cases}$ \\
\hline Top surfaces & S_top & $q(\tau)= \begin{cases}q_{c}+q_{r}+q_{a} & (p(\tau)=0) \\
q_{p} & (p(\tau)=1)\end{cases}$ \\
\hline Outlet hole surfaces & S_hole & $q(\tau)= \begin{cases}q_{c}+q_{r}+q_{a} & \left(z \geq z \_ \text {mono }-h \_ \text {hole }\right) \\
q_{c}+q_{r} & \left.\left(z_{\text {up }}<z<z \_ \text {mono }-h\right\lrcorner \text { hole }\right) \\
q_{w} & \left(z \leq z_{\text {up }}\right)\end{cases}$ \\
\hline
\end{tabular}

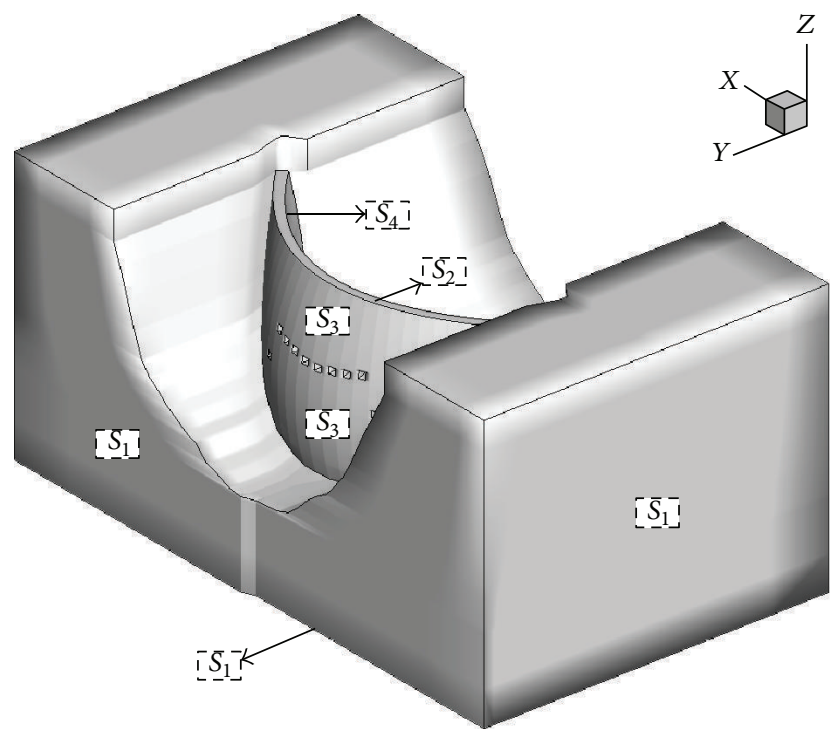

Figure 6: Preliminary defined surface groups.
A few remarks should be made on the setup rule in Table 2

(i) The in-rock vertical surfaces generated by the modelside cutting are adiabatic because the horizontal heat transfer in the infinite rock is symmetrical to these surfaces.

(ii) The ground temperature beneath the upper $6 \mathrm{~m}$ of the surface of the Earth maintains a nearly constant temperature between $10^{\circ} \mathrm{C}$ and $16^{\circ} \mathrm{C}$ [36], depending on the site latitude. Let $Z_{g}$ denote the upper level of the constant temperature layer, and the thermal boundaries below $Z_{g}$ on $S_{1}$ can be expressed as the first-type boundary condition.

(iii) $Z_{\text {up }}$ and $Z_{\text {down }}$ are used to represent the upstream water level and downstream water level, and the impounding plan should be drawn up when making prediction.

(iv) A protection scheme should be established based on the design plan when a prediction is conducted 


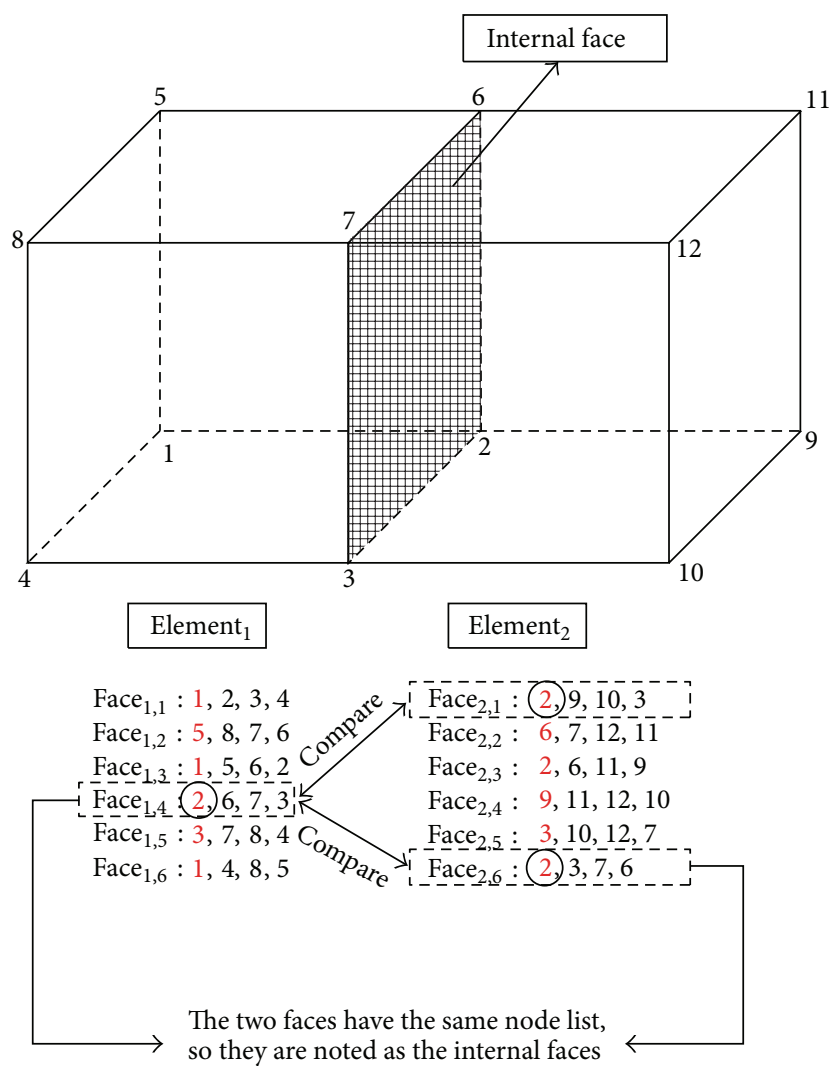

FIGURE 7: Example of recognizing the inside faces. The red bold number is the minimum node number of the face.

or based on the actual condition when simulating the past. $p(\tau)$ is the variable that denotes whether protection is covered at time $\tau$. In large engineering projects, $p(\tau)$ is also relevant to the surface locations. Some projects may be dependent on the lift and others on the elevation, in which case $p(\tau$, lift_ID) or $p(\tau, z)$ is used to represent the protection status.

(v) $h$ hole represents the height of the hole. When concrete is cast over the top of the holes, the sun barely shines into the spillway holes constructed inside the dam body; thus, solar irradiation is not considered in these areas.

(vi) $q_{a}$ differs from all the surfaces because the inclination of every element face is not the same.

Algorithm 1 mentions that the external surfaces should be initially recognized. Each internal face for the FE meshes must have the same node list with only one face of another element. One way to extract the external surfaces is to check all the internal faces by comparing all the faces of the model. However, this method costs too much time for large models. In this study, a minimum node number is used as a label to accelerate the extracting process, the details of which are described in Algorithm 2. Figure 7 shows an example where two elements are adjacent on one internal face.
The detection algorithm of $S_{5}, S_{6}$, and $S_{-}$rock mentioned in Algorithm 1 can be executed in Algorithm 3.

A remark should be noticed that the algorithms can also be applied as a preprocessing facility for a third-party FEM software package. An improvement which should be made on the origin Algorithm 1 is that the surface sets extracted at each step should be separately stored and without executing the FEM solver.

4.4. Software Development. In this study, a user-friendly interface for data input is developed based on the EXCEL software. The embedded VBA programming language can be utilized to provide a convenient user interface and to handle the data automatically. Several forms are generated for users to collect the information required in the simulation, including climate condition, construction procedure, material properties, and predefined surfaces. The form style is concise, explicit, and easy-to-use.

A C-language-based program is compiled to process the data input from the spreadsheet and the FE meshes. Algorithm 1 to Algorithm 3 are implemented in the program.

Several commercial or free source FEM packages exist. Our developed program can be exported as requested provided that the input format is known. In this study, MSC.Marc [37] is used as the third-party FEM solver because of its quickness and stable benchmark.

Common users found the postprocessing module of MSC.Marc to be inconvenient and awkward. A program is developed to decode the .t16 result output file for fast, automatic, and easy-to-use postprocessing. A customized form, which can be found in the EXCEL interface, offers two options: desired nodes and desired contour time. The developed program can then extract and plot the data, including the time-temperature curves and temperature contours.

Figure 8 summarizes the entire flow process.

\section{Case Study}

5.1. Engineering Description. The site of the Xiluodu hydropower project is located in the lower reach of the Jinsha River, Yunnan Province in Southwest China. The geographic coordinate is $28^{\circ} 13^{\prime} 02^{\prime \prime} \mathrm{N}, 103^{\circ} 33^{\prime} 46^{\prime \prime} \mathrm{E}$. The project is designed as a dome dam that is double curved in both horizontal and vertical planes and with a maximum height of $285.5 \mathrm{~m}$ and a crest length of $700 \mathrm{~m}$. The footing sits upon the riverbed foundation on a $324.5 \mathrm{~m}$ elevation. A total of 31 monoliths are planted across the river. Seven $12.5 \mathrm{~m} \times 13.5 \mathrm{~m}$ surface spillways and eight $6 \mathrm{~m} \times 6.7 \mathrm{~m}$ deep outlet holes are arranged in the arch dam body. The transversal section of the dam is curve shaped and is $14 \mathrm{~m}$ wide at the crest and $60 \mathrm{~m}$ wide at the footing.

5.2. Construction Schedule. The dam started casting concrete in March 2009. The dam comprises about 2100 lifts within an approximately five-year construction period because of considerations for proper concrete casting and to avoid thermal cracks. A total of 1961 lifts were completed by June 2013. The detailed casting-time sequence was recorded. 


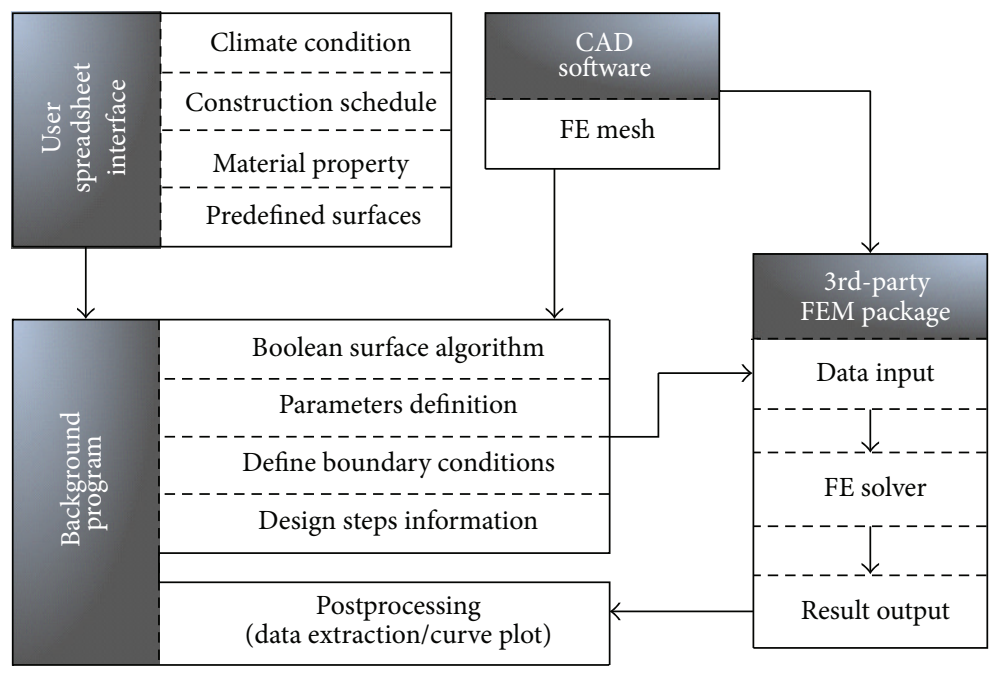

FIGURE 8: Flowchart of the software development.

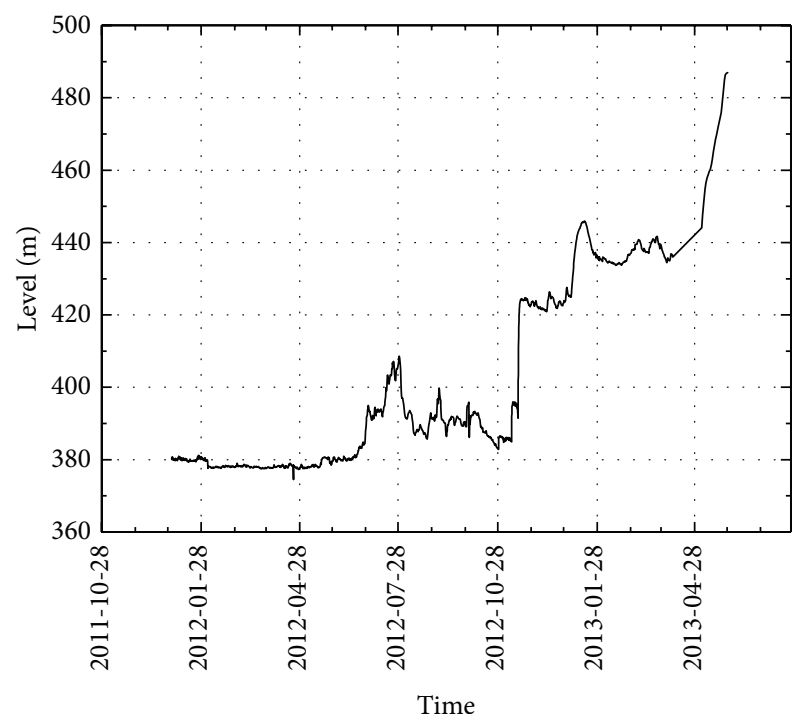

FIGURE 9: Water level process during construction.

The upstream cofferdam was demolished in March 2012, and the reservoir was impounded. The upstream water level was measured and recorded (see Figure 9).

5.3. Climate Conditions. The site is located in a V-shaped canyon of the Jinsha River and is subjected to a subtropical climate. A nearby hydrologic station records the weather data daily. The ambient temperatures and wind speeds from January 2009 to May 2013 are shown in Figure 10, in which the temperatures over the years can be considered repeated sinusoidal curves on the basis of (7).

A meteorological station is located near the dam site in Zhaotong, and the fundamental solar measurement data were used as the reference for the simulation. Table 3 shows the

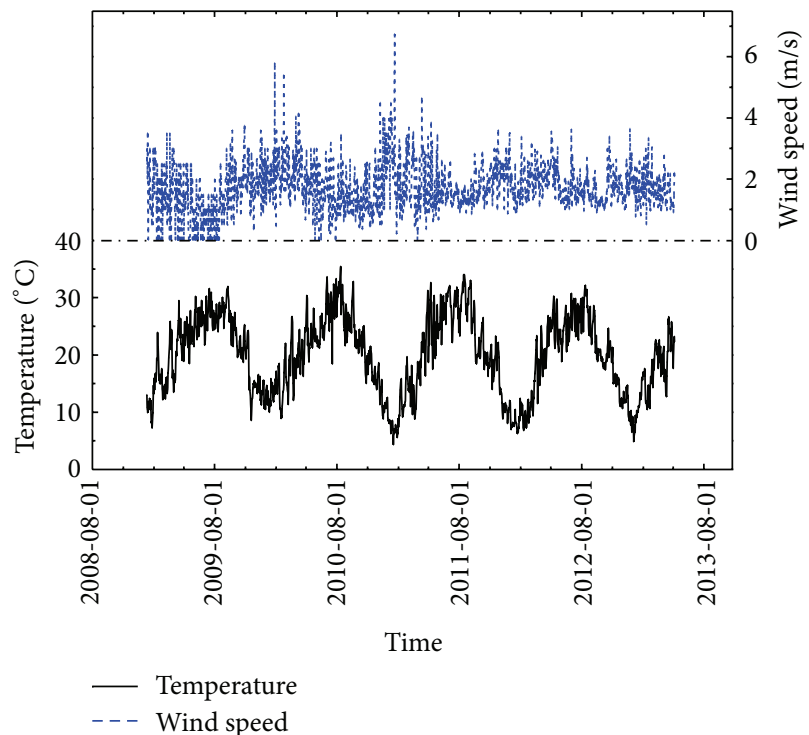

FIGURE 10: Weather curve (air temperatures and wind speeds).

data for the solar irradiation calculation, which acts as the basic design parameters in the simulation.

Table 3 shows the calculation result of the solar radiation, where $E_{\mathrm{Beam}}^{*}$ and $E_{\mathrm{Diff}}^{*}$ are the radiation values at solar noon, $\overline{E_{\mathrm{Beam}}}$ and $\overline{E_{\mathrm{Diff}}}$ are the average radiation value's during daytime, and $\overline{E_{\text {Sun }}^{V}}$ and $\overline{E_{\text {Sun }}^{H}}$ are, respectively, the average total solar input for the vertical and horizontal structure surfaces.

$\eta_{\text {Beam }}$ and $\eta_{\text {Diff }}$ are the station measurements, based on which the values of $E_{\text {Beam }}^{*}$ and $E_{\text {Diff }}^{*}$ are calculated by (16) and (18) by setting $H=0 . H_{\text {Rise }}$ and $H_{\text {Set }}$ can then be obtained through a multiple trial computation when $\beta$ reaches $0^{\circ}$. Averaging $E_{\text {Beam }}, E_{\text {Diff }}$, and $E_{\text {Sun }}$ from $H_{\text {Rise }}$ to $H_{\text {Set }}$ yields the result of $\overline{E_{\text {Beam }}}, \overline{E_{\text {Diff }}}$, and $\overline{E_{\text {Sun }}}$. 


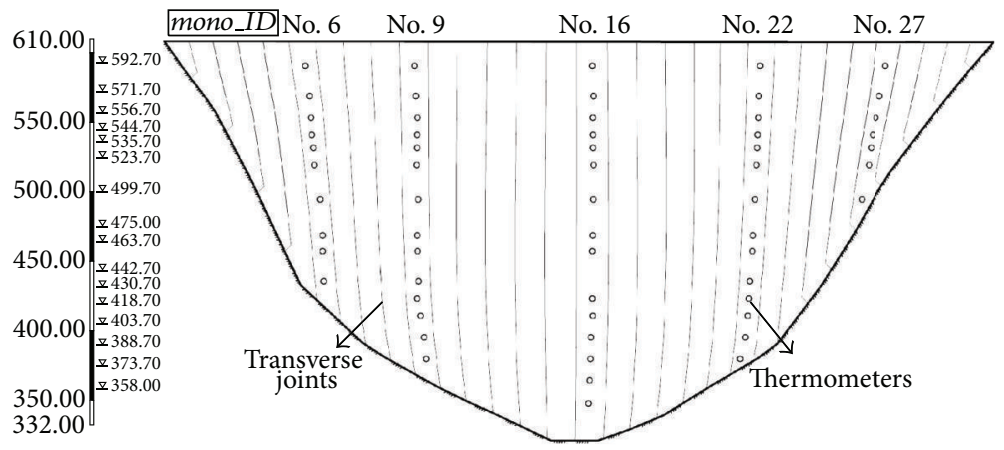

FigURE 11: Instruments setup (viewed from upstream to downstream).

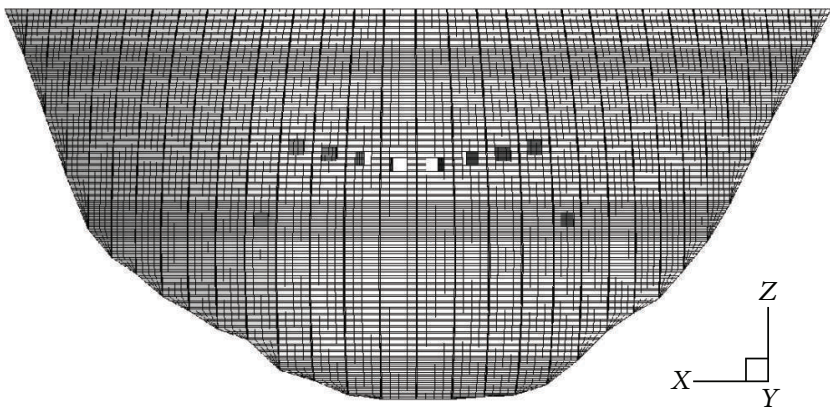

FIGURE 12: Finite element meshes of the dam body.

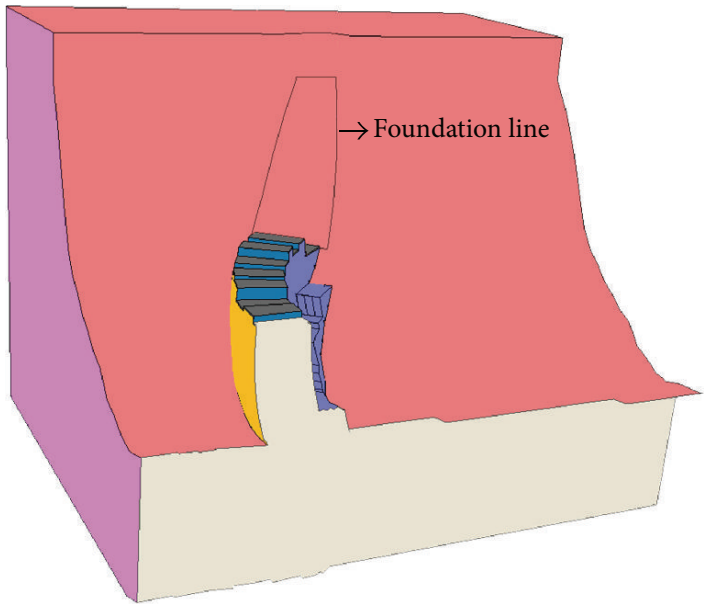

(a) Time when 500th lift cast

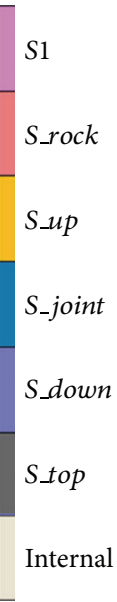

Internal

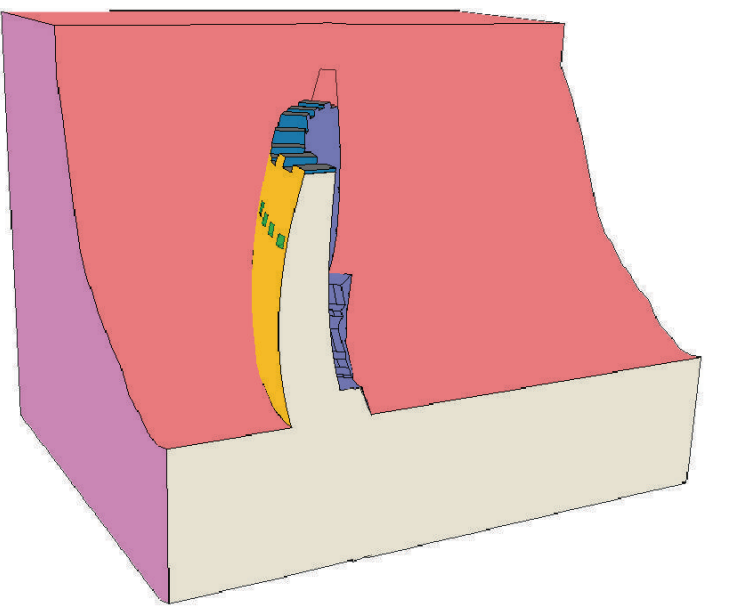

(b) Time when 1000th lift cast
$S 1$

S_rock

S_up

$S_{-}$joint

S_down

S_top

Internal

FIGURE 13: Sketch of surface taxonomy map.

(1) for $i=1,2, \ldots$, num_elements do // Searching all the elements

(2) Request the element type and the count of faces in one element is stored as $S$.

(3) for $j=1,2, \ldots, S$ do // Searching all the faces

(4) Obtain the minimum node number of the face nodes, labeled as Node $e_{i, j}$.

(5) end loop $j$

(6) end loop $i$

(7) Search for the faces with the same value of $\operatorname{Node}_{i, j}$.

(8) Compare the topology of the faces. If two faces have the same nodes list, note them as internal faces.

(9) All the faces that have not been noted can be stored as the external surfaces. 
(1) $S_{5}=S_{\_}$all $-S_{1}-S_{2}-S_{3}-S_{4}$

(2) for $i=1,2, \ldots$, num mono -1 do

(3) $\quad S_{6}=(($ Surface of elements with mono_ID [lift_ID $]=i) \wedge($ those with mono_ID [lift_ID $\left.\left.]=i+1\right)\right) \vee S_{6}$

(4) end loop $i$

(5) Recognize all external surfaces of elements with mono $I D>0$, and noted them as $S_{-}$base.

// Searching for only the base elements based on Algorithm 2, that means the foundation faces the dam sits upon will also be included.

(6) S_rock $=$ S_base $-S_{1}$.

Algorithm 3: Initial detection of the hole surfaces $S_{5}$, transverse joint surfaces $S_{6}$, and rock-exposed surfaces $S_{-}$rock.

TABLE 3: Calculation of solar irradiation.

(a)

\begin{tabular}{llr}
\hline Xiluodu Dam & Latitude: $28^{\circ} 13^{\prime} 02^{\prime \prime} \mathrm{N}$ & Longitude: $103^{\circ} 33^{\prime} 46^{\prime \prime} \mathrm{E}$ \\
\hline Zhaotong Station & Latitude: $27^{\circ} 19^{\prime} 48^{\prime \prime} \mathrm{N}$ & Longitude: $103^{\circ} 45^{\prime} 00^{\prime \prime} \mathrm{E}$ \\
\hline
\end{tabular}

(b)

\begin{tabular}{lcccccc}
\hline & Jan 21st & Feb 21st & Mar 21st & Apr 21st & May 21st & Jun 21st \\
\hline$D$ & 21 & 52 & 80 & 111 & 141 & 172 \\
$\eta_{\text {Beam }}$ & 0.362 & 0.369 & 0.448 & 0.479 & 0.525 & 0.504 \\
$\eta_{\text {Diff }}$ & 2.080 & 2.084 & 1.835 & 1.791 & 1.707 & 1.820 \\
$E_{\text {Beam }}^{*}\left(\mathrm{~W} / \mathrm{m}^{2}\right)$ & 674.24 & 719.12 & 750.84 & 764.69 & 762.99 & 758.19 \\
$E_{\text {Diff }}^{*}\left(\mathrm{~W} / \mathrm{m}^{2}\right)$ & 189.32 & 204.92 & 217.25 & 223.84 & 224.33 & 223.10
\end{tabular}

$H_{\text {Set }}-H_{\text {Rise }}(\mathrm{h}) \quad 18.6-8.0=10.6 \quad 19-7.7=11.3 \quad 19.2-7.3=11.9 \quad 19.5-6.7=12.8 \quad 19.8-6.3=13.5 \quad 19.9-6.2=13.8$

\begin{tabular}{|c|c|c|c|c|c|c|}
\hline$\overline{E_{\text {Beam }}}\left(\mathrm{W} / \mathrm{m}^{2}\right)$ & 466.16 & 504.89 & 541.53 & 551.07 & 547.52 & 546.35 \\
\hline$\overline{E_{\text {Diff }}}\left(\mathrm{W} / \mathrm{m}^{2}\right)$ & 132.36 & 143.80 & 154.89 & 158.71 & 158.28 & 157.89 \\
\hline$\overline{E_{\text {Sun }}^{V}}\left(\mathrm{~W} / \mathrm{m}^{2}\right)$ & 401.51 & 360.70 & 280.32 & 162.93 & 91.00 & 71.70 \\
\hline \multirow[t]{2}{*}{$E_{\text {Sun }}^{H}\left(\mathrm{~W} / \mathrm{m}^{2}\right)$} & 378.29 & 448.80 & 521.64 & 561.99 & 568.09 & 568.47 \\
\hline & Jul 21st & Aug 21st & Sep 21st & Oct 21st & Nov 21st & Dec 21st \\
\hline$D$ & 202 & 233 & 264 & 294 & 325 & 355 \\
\hline$\eta_{\text {Beam }}$ & 0.512 & 0.546 & 0.487 & 0.448 & 0.391 & 0.365 \\
\hline$\eta_{\text {Diff }}$ & 1.820 & 1.708 & 1.833 & 1.883 & 2.025 & 2.076 \\
\hline$E_{\text {Beam }}^{*}\left(\mathrm{~W} / \mathrm{m}^{2}\right)$ & 751.02 & 754.78 & 740.12 & 707.95 & 667.55 & 650.57 \\
\hline$E_{\text {Diff }}^{*}\left(\mathrm{~W} / \mathrm{m}^{2}\right)$ & 222.60 & 220.96 & 214.20 & 201.56 & 187.34 & 181.68 \\
\hline$H_{\text {Set }}-H_{\text {Rise }}(\mathrm{h})$ & $19.9-6.5=13.4$ & $19.6-6.7=12.9$ & $19-6.9=12.1$ & $18.4-7.2=11.2$ & $18.1-7.6=10.5$ & $18.2-7.9=10.3$ \\
\hline$\overline{E_{\text {Beam }}}\left(\mathrm{W} / \mathrm{m}^{2}\right)$ & 547.62 & 539.21 & 526.69 & 498.23 & 463.08 & 446.57 \\
\hline$\overline{E_{\text {Diff }}}\left(\mathrm{W} / \mathrm{m}^{2}\right)$ & 158.32 & 155.75 & 150.59 & 142.10 & 131.67 & 129.80 \\
\hline$\overline{E_{\text {Sun }}^{V}}\left(\mathrm{~W} / \mathrm{m}^{2}\right)$ & 89.61 & 157.91 & 270.12 & 360.71 & 401.60 & 407.44 \\
\hline$E_{\mathrm{Sun}}^{H}\left(\mathrm{~W} / \mathrm{m}^{2}\right)$ & 568.91 & 550.41 & 507.16 & 441.23 & 375.37 & 348.70 \\
\hline
\end{tabular}

5.4. Instrument Setup. A number of digital thermometers are embedded $0.10 \mathrm{~m}$ under the dam surfaces to monitor the concrete surface temperature distribution. Pairs of thermometers are arranged at the same elevation in the same concrete lift: one at the upstream surface and the other at the downstream surface. Monoliths number 6 , number 9 , number 16 , number 22 , and number 27 are selected as monitoring sections. Figure 11 shows the instrument layout of the upstream surface of the dam.
5.5. Material Properties. A double exponent hydration model [38] of concrete is applied in this engineering, which can be expressed as

$$
\theta=\theta_{0}\left[s\left(1-e^{-m_{1} \tau}\right)+(1-s)\left(1-e^{-m_{2} \tau}\right)\right],
$$

where $\theta$ is the adiabatic temperature rise and $\theta_{0}, s, m_{1}$, and $m_{2}$ are the fitting parameters. The technical reports of the material experiments reveal that three main types of concrete 


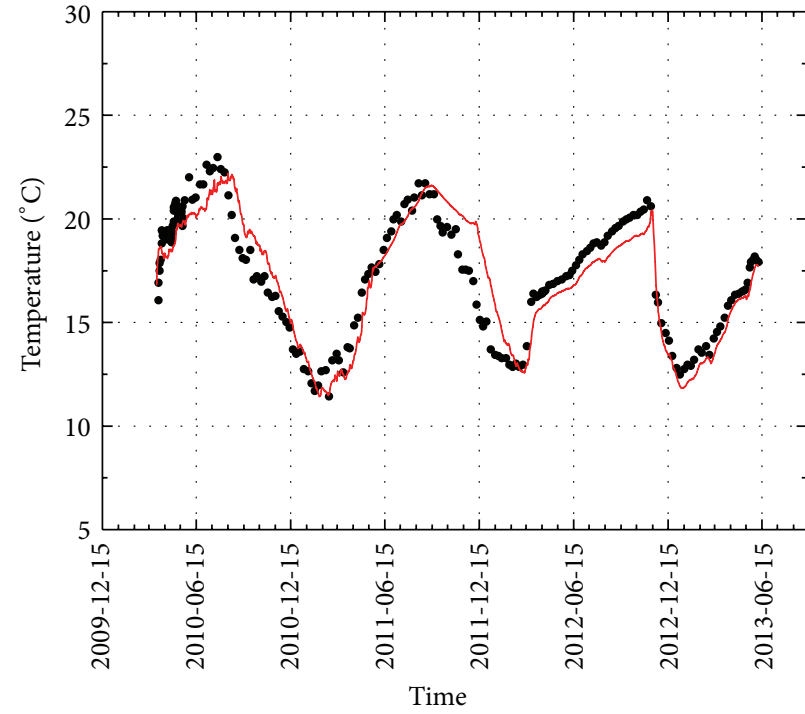

- Monitoring - Simulation

(a) mono_ID $=16$, elevation $=358.0$

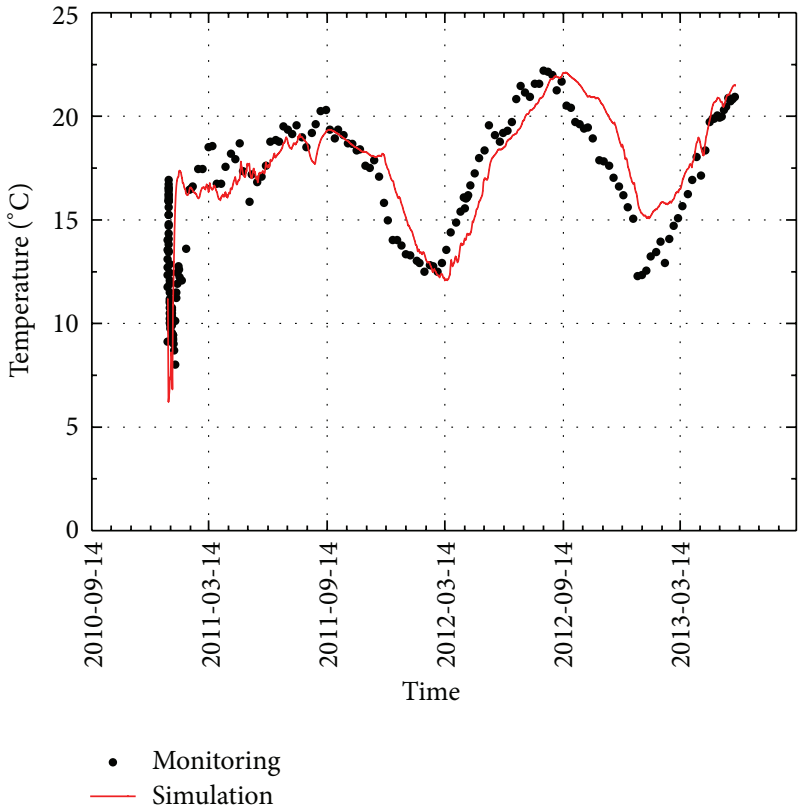

(b) mono_ID $=22$, elevation $=387.7$

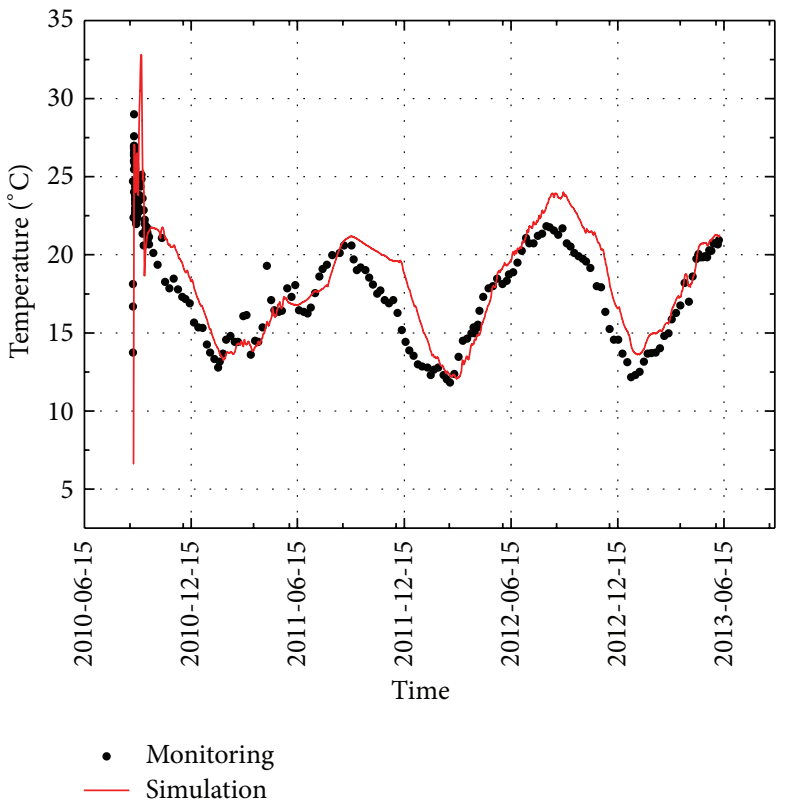

(c) mono_ID $=16$, elevation $=403.7$

FIGURE 14: Simulation results.

are used in the dam construction. The material properties are listed in Table 4.

5.6. Simulation Model. The 3D dam-foundation system is discretized into hexahedral meshes. A total of 154,008 elements represent the dam body, and 28,026 elements represent the foundation. The total number of nodes is 216,837 . The FE mesh layout of the dam body is shown in Figure 12.

\section{Results and Discussions}

6.1. Surface Taxonomy. The surface procedure mentioned in this study is implemented as a preprocessing facility. The surface groups classified at each step are stored. Figure 13 shows the results of the surface taxonomy map at the 500th and 700th steps, in which different colors represent different surface groups. The FE model is split along the central river to show clearly the upstream and downstream faces. The 


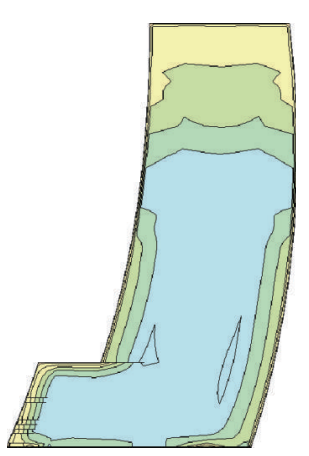

(a) June 2011

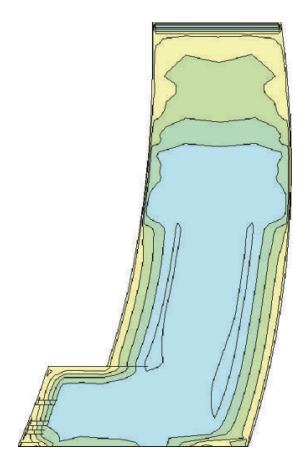

(b) July 2011

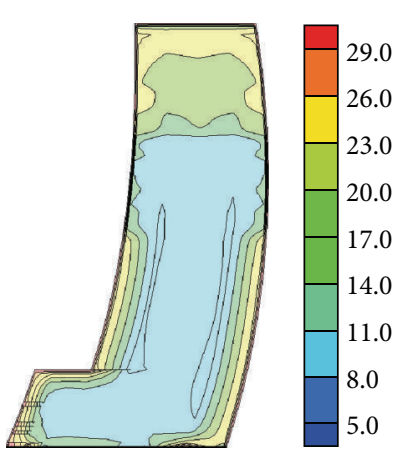

(c) August 2011

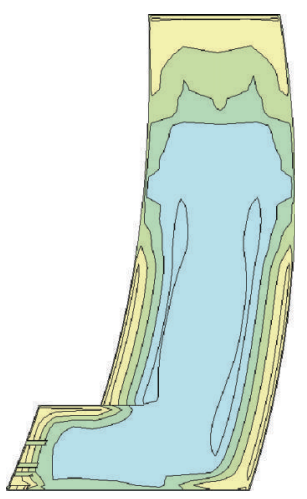

(d) September 2011

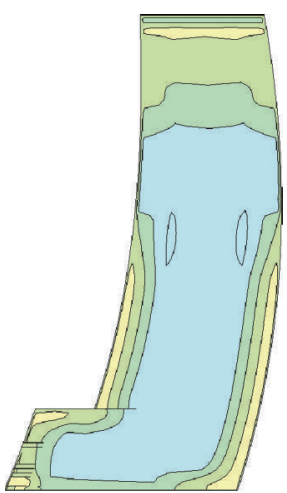

(e) October 2011

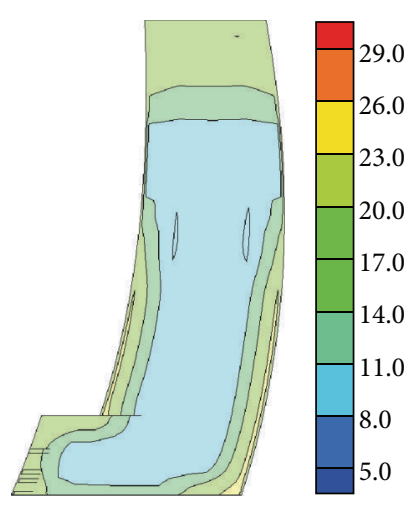

(f) November 2011

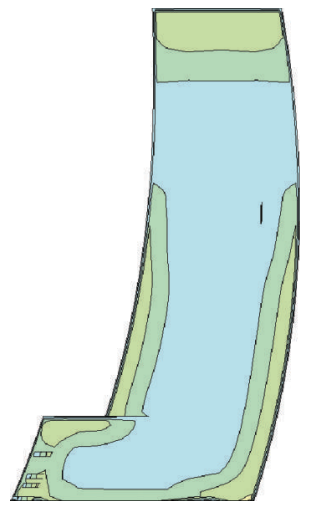

(g) December 2011

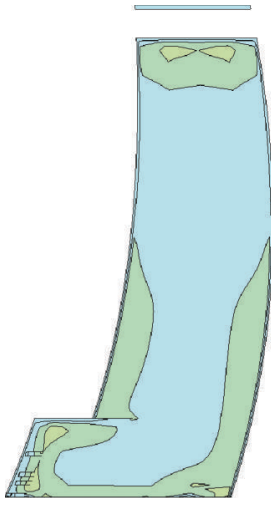

(h) January 2012

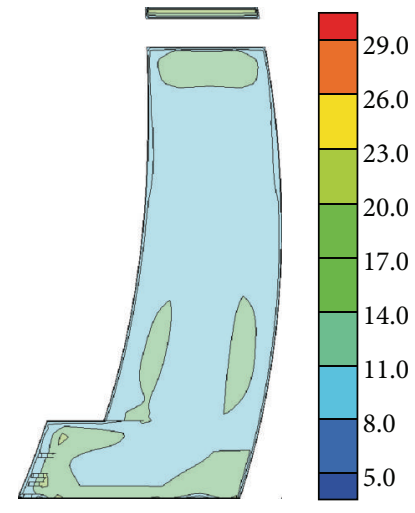

(i) February 2012

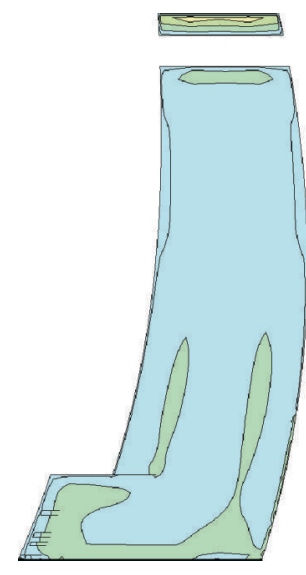

(j) March 2012

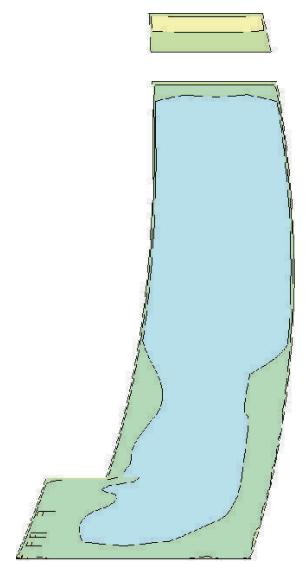

(k) April 2012

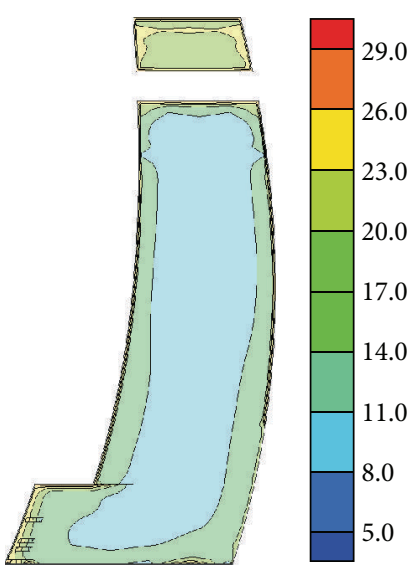

(l) May 2012

FIgURE 15: Temperature contour of the section in monolith 15 throughout a year from June 2011 to May 2012.

external surfaces are correctly extracted. The surface groups by the automatic Boolean-based algorithms are reasonable.

6.2. Verification. The calculation temperature history of nodes that are near the positions of the embedded thermometers is extracted by the program and compared with the monitored data. It is found that they have a good agreement, which verifies the correctness of the external heat transfer analysis method present in this study. Three thermometers are picked out as shown in Figure 14.

6.3. Temperature Distribution. The simulation result is automatically transported into Tecplot to draw the temperature contour, as mentioned in Section 4.4. Figure 15 shows the temperature section of monolith 15 through a whole year 
TABLE 4: Material properties of concrete.

\begin{tabular}{|c|c|c|c|c|}
\hline \multicolumn{2}{|c|}{ Material property } & Type I & Type II & Type III \\
\hline \multirow{3}{*}{ Basic heat transfer } & $C_{p}\left(\mathrm{~J} / \mathrm{kg} \cdot{ }^{\circ} \mathrm{C}\right)$ & 943.0 & 934.0 & 860.0 \\
\hline & $\rho\left(\mathrm{kg} / \mathrm{m}^{3}\right)$ & 2663 & 2663 & 2663 \\
\hline & $\lambda\left(\mathrm{W} / \mathrm{m} \cdot{ }^{\circ} \mathrm{C}\right)$ & 2.14 & 2.14 & 2.14 \\
\hline \multirow{4}{*}{ Hydration model } & $\theta_{0}\left({ }^{\circ} \mathrm{C}\right)$ & 26.3 & 25.5 & 24.7 \\
\hline & $m_{1}$ & 0.252 & 0.252 & 0.252 \\
\hline & $m_{2}$ & 0.025 & 0.025 & 0.025 \\
\hline & $s$ & 0.6 & 0.6 & 0.6 \\
\hline Radiation & $F_{r}$ & 0.88 & 0.88 & 0.88 \\
\hline \multirow{3}{*}{ Air-side convection } & $a$ & 0.99 & 0.99 & 0.99 \\
\hline & $b$ & 0.21 & 0.21 & 0.21 \\
\hline & $m$ & 1.0 & 1.0 & 1.0 \\
\hline \multirow{3}{*}{ Solar input } & $\zeta$ & 0.50 & 0.50 & 0.50 \\
\hline & $g$ for upstream & 0.07 & 0.07 & 0.07 \\
\hline & $g$ for downstream & 0.20 & 0.20 & 0.20 \\
\hline \multirow{2}{*}{ Protection } & $\lambda_{p}$ for quilt covers $\left(\mathrm{W} / \mathrm{m} \cdot{ }^{\circ} \mathrm{C}\right)$ & 0.045 & 0.045 & 0.045 \\
\hline & $\lambda_{p}$ for PFP boards $\left(\mathrm{W} / \mathrm{m} \cdot{ }^{\circ} \mathrm{C}\right)$ & 0.036 & 0.036 & 0.036 \\
\hline
\end{tabular}

from June 2011 to May 2012. Conclusions can be drawn from these contour maps as follows.

(i) External thermal flux has great impact on the area underneath the boundary surfaces, for the temperature varies following the seasonal change.

(ii) The arch dam seals the joint layer by layer and starts cooling the sealed regions before the sealing time. We can see that the weather-affected border is obviously narrow in some lifts because of the strong internal cooling source, like $(\mathrm{d}) \sim(\mathrm{f})$ in the figure.

(iii) The after-sealed internal concrete, located a particular height below the top elevation, is not sensitive to the external weather. The temperature does not change much throughout a whole year.

(iv) The surface temperature gradient is more obvious in summer than in winter, for the dam's sealing temperature is $13^{\circ} \mathrm{C}$, much lower than the average summer air temperature and closer to the average winter air temperature.

(v) The new-cast lift can reach a relatively high temperature peak due to the hydration reaction and induce a temperature gradient with the old concrete and the external surfaces.

(vi) The ground temperature has impact on the footing region where the temperature is higher than the sealing temperature.

(vii) The upstream face regions which contact with water are mainly affected by the water temperature after March 2012, when the reservoir starts impounding, like $(j) \sim(i)$ in the figure.

(viii) The blank area is the outlet hole, like (h) (i) in the figure. The hollow hole makes the hole wall contact with the air, which generates a temperature gradient near the surface.

\section{Conclusions}

The external heat transfer of dams during the construction phase is complex because such transfer is location specific and time varying. A sound model for the external heat transfer of dams during construction is developed in this study. First, a mathematical model of five external thermal flux factors, namely, air-side convection, electromagnetic radiation, absorbed solar input, water-side convection, and surface insulation effect, is proposed. A surface procedure for FE analysis is also established based on Boolean operations. The proposed procedure can extract external surfaces and can create a taxonomy of surfaces for proper boundary conditions. An arch dam that is under construction in China with a height of $285 \mathrm{~m}$ is used to test the proposed method. The method can precisely extract the external surface and can correctly classify these surfaces in each step. The numerical result is compared with the monitoring temperatures. The result shows good agreement, thereby verifying the validity of the proposed method.

\section{Appendix}

Hour angle $H$ is defined as the angular displacement of the sun east or west of the local meridian due to the rotation of the earth. To obtain $H$, the equation of time should be calculated as follows:

$$
\begin{array}{r}
E T=2.2918[0.0075+0.1868 \cos \Gamma-3.2077 \sin \Gamma \\
-1.4615 \cos (2 \Gamma)-4.089 \sin (2 \Gamma)],
\end{array}
$$

where ET is expressed in minutes and

$$
\Gamma=360^{\circ} \frac{D-1}{365} .
$$


Then the apparent solar time (AST) can be expressed in the following equation:

$$
\mathrm{AST}=\frac{\mathrm{LST}+\mathrm{ET} / 60+(\mathrm{LON}-\mathrm{LSM})}{15}
$$

where LST is the local standard time, decimal hours, LSM is the longitude of local standard time meridian, positive for east, and LON is the longitude of site. For example, China mainland's LSM is 120 .

Finally the hour angle $H$ can be given by

$$
H=15(\mathrm{AST}-12) \text {. }
$$

A remark is notable that when $H=0, \beta$ reaches the daily maximum angle of $\pi / 2-|L-\delta|$, the very moment which is called the solar noon.

\begin{tabular}{|c|c|}
\hline$T:$ & Temperature $\left({ }^{\circ} \mathrm{C}\right)$ \\
\hline$C_{p}:$ & Specific heat $\left(\mathrm{J} / \mathrm{kg} \cdot{ }^{\circ} \mathrm{C}\right)$ \\
\hline$q:$ & External heat flux $\left(\mathrm{W} / \mathrm{m}^{2}\right)$ \\
\hline$q_{c}:$ & $\begin{array}{l}\text { Air-side convection heat exchange rate } \\
\left(\mathrm{W} / \mathrm{m}^{2}\right)\end{array}$ \\
\hline$q_{a}:$ & $\begin{array}{l}\text { Absorbed solar irradiation heat flux } \\
\left(\mathrm{W} / \mathrm{m}^{2}\right)\end{array}$ \\
\hline$q_{p}:$ & $\begin{array}{l}\text { Heat exchange rate through the protection } \\
\left(\mathrm{W} / \mathrm{m}^{2}\right)\end{array}$ \\
\hline$q_{r}:$ & $\begin{array}{l}\text { Radiative electromagnetic heat flux } \\
\left(\mathrm{W} / \mathrm{m}^{2}\right)\end{array}$ \\
\hline$q_{w}:$ & Water-side convection heat flux $\left(\mathrm{W} / \mathrm{m}^{2}\right)$ \\
\hline$h_{c}:$ & Air-side convection coefficient $\left(\mathrm{W} / \mathrm{m}^{2{ }^{\circ}} \mathrm{C}\right)$ \\
\hline$n:$ & Normal direction \\
\hline$F_{r}:$ & Emissivity of surface \\
\hline$T_{a}:$ & Ambient temperature $\left({ }^{\circ} \mathrm{C}\right)$ \\
\hline$V_{w}:$ & Wind speed $(\mathrm{m} / \mathrm{s})$ \\
\hline$N:$ & The normal direction to the surface \\
\hline$f:$ & $\begin{array}{l}\text { Internal heat source per unit volume } \\
\left(\mathrm{W} / \mathrm{m}^{3}\right)\end{array}$ \\
\hline$a:$ & Empirical parameter in (4) \\
\hline$b:$ & Empirical parameter in (4) \\
\hline$m:$ & Empirical parameter in (4) \\
\hline$T_{1}:$ & Measured air temperature $1\left({ }^{\circ} \mathrm{C}\right)$ \\
\hline$T_{2}:$ & Measured air temperature $2\left({ }^{\circ} \mathrm{C}\right)$ \\
\hline$H_{1}:$ & Measured time $1(\mathrm{~h})$ \\
\hline$H_{2}:$ & Measured time $2(\mathrm{~h})$ \\
\hline$H_{\text {Mean }}$ : & $\begin{array}{l}\text { The middle hour of day between the } \\
\text { temperature peak and valley (h) }\end{array}$ \\
\hline$T_{\text {Max }}:$ & Maximum temperature of a year $\left({ }^{\circ} \mathrm{C}\right)$ \\
\hline$T_{\text {Min }}:$ & Minimum temperature of a year $\left({ }^{\circ} \mathrm{C}\right)$ \\
\hline$D_{\text {Anu }}:$ & The middle day between $T_{\mathrm{Max}}$ and $T_{\mathrm{Min}}(\mathrm{d})$ \\
\hline$T_{\text {Anu }}:$ & Mean temperature throughout a year $\left({ }^{\circ} \mathrm{C}\right)$ \\
\hline$C:$ & Heat capacity matrix \\
\hline$K:$ & Thermal conductivity matrix \\
\hline Q: & Heat flux vector \\
\hline
\end{tabular}

\section{Nomenclature}

$V: \quad 3 D$ domain space of FEM

$[K]$ : Symbol for degree Kelvin

$\left[{ }^{\circ} \mathrm{C}\right]$ : Symbol for degree Celsius

$H$ : $\quad$ Hour angle $\left({ }^{\circ}\right)$

L: $\quad$ Latitude angle $\left({ }^{\circ}\right)$

$b_{p}$ : The width of each protection (m)

$E_{\text {Sun }}$ : The total solar energy input reaching the structure surface $\left(\mathrm{W} / \mathrm{m}^{2}\right)$

$E_{\text {Beam }}$ : Beam (direct) component of solar radiation $\left(\mathrm{W} / \mathrm{m}^{2}\right)$

$E_{\text {Diff: }}$ Diffuse component of solar radiation $\left(\mathrm{W} / \mathrm{m}^{2}\right)$

$E_{\text {Refl }}$ : Ground reflector component of solar radiation $\left(\mathrm{W} / \mathrm{m}^{2}\right)$

$Y_{\text {Beam }}$ : Irradiation coefficient of the beam component

$Y_{\text {Diff: }}$ Irradiation coefficient of the diffuse component

$E_{0}$ : $\quad$ Extraterrestrial solar radiant flux $\left(\mathrm{W} / \mathrm{m}^{2}\right)$

$m: \quad$ The relative air mass

$g$ : $\quad$ Ground reflectance factor of foreground

$E_{\mathrm{sc}}: \quad$ Solar constant $\left(\mathrm{W} / \mathrm{m}^{2}\right)$

$h_{w}$ : Water-side convection coefficient between $\left(\mathrm{W} / \mathrm{m}^{2 \circ} \mathrm{C}\right)$

$T_{w}: \quad$ Water temperature $\left({ }^{\circ} \mathrm{C}\right)$

$H_{\text {Rise }}$ : Sunrise hour (h)

$H_{\text {Set }}$ : Sunset hour (h).

\section{Greek Symbols}

$\rho: \quad$ Density $\left(\mathrm{kg} / \mathrm{m}^{3}\right)$

$\lambda$ : Thermal conductivity $\left(\mathrm{W} / \mathrm{m} \cdot{ }^{\circ} \mathrm{C}\right)$

$\tau:$ Time (s)

$\eta$ : Parameter representing optical depths

$\zeta$ : Absorptivity of the exposed surface

$\lambda_{p}$ : The conduction coefficient of each protection $\left(\mathrm{W} / \mathrm{m} \cdot{ }^{\circ} \mathrm{C}\right)$

$\psi$ : Surface azimuth $\left({ }^{\circ}\right)$

$\sigma$ : Stefan-Boltzmann constant $\left(\mathrm{W} \mathrm{m}^{-2} \mathrm{~K}^{-4}\right)$

$\mu$ : Inclination angle of the structure surface $\left({ }^{\circ}\right)$

$\gamma$ : The surface-solar azimuth angle $\left({ }^{\circ}\right)$

$\beta$ : Solar altitude angle $\left({ }^{\circ}\right)$

$\phi$ : Solar azimuth angle $\left(^{\circ}\right)$

$\theta$ : Angle of incidence $\left({ }^{\circ}\right)$.

\section{Acknowledgments}

This work is supported by the National "973" Researching Project of China (no. 2013CB035902), Research Project of State Key Laboratory of Hydroscience and Engineering of Tsinghua University (no. 2012-KY-4), and the National Nature Science Foundation of China (no. 51279087).

\section{References}

[1] J. M. Crow, "The concrete conundrum," Chemistry World, vol. 5, no. 3, pp. 62-66, 2008. 
[2] Y. Wu and R. Luna, "Numerical implementation of temperature and creep in mass concrete," Finite Elements in Analysis and Design, vol. 37, no. 2, pp. 97-106, 2001.

[3] F.-J. Ulm and O. Coussy, "What is a "massive" concrete structure at early ages? Some dimensional arguments," Journal of Engineering Mechanics, vol. 127, no. 5, pp. 512-522, 2001.

[4] R. R. Wertz, "Special report: three gorges dam project. Exploring Chinese history," 2011, http://www.ibiblio.org/chinesehistory/contents/07spe/specrep01.html.

[5] H. Demir, "Experimental and numerical studies of natural convection from horizontal concrete cylinder heated with a cylindrical heat source," International Communications in Heat and Mass Transfer, vol. 37, no. 4, pp. 422-429, 2010.

[6] Y. Lee, M.-S. Choi, S. T. Yi, and J. K. Kim, "Experimental study on the convective heat transfer coefficient of early-age concrete," Cement and Concrete Composites, vol. 31, no. 1, pp. 60-71, 2009.

[7] G. F. Jones and R. W. Jones, "Steady-state heat transfer in an insulated, reinforced concrete wall: theory, numerical simulations, and experiments," Energy and Buildings, vol. 29, no. 3, pp. 293-305, 1999.

[8] P. Léger and S. Seydou, "Seasonal thermal displacements of gravity dams located in northern regions," Journal of Performance of Constructed Facilities, vol. 23, no. 3, pp. 166-174, 2009.

[9] P. Léger and M. Leclerc, "Hydrostatic, temperature, timedisplacement model for concrete dams," Journal of Engineering Mechanics, vol. 133, no. 3, pp. 267-277, 2007.

[10] F. Sheibany and M. Ghaemian, "Effects of environmental action on thermal stress analysis of karaj concrete arch dam," Journal of Engineering Mechanics, vol. 132, no. 5, pp. 532-544, 2006.

[11] F. Jin, Z. Chen, J. Wang, and J. Yang, "Practical procedure for predicting non-uniform temperature on the exposed face of arch dams," Applied Thermal Engineering, vol. 30, no. 14-15, pp. 2146-2156, 2010.

[12] M. Cervera, J. Oliver, and T. Prato, "Simulation of construction of RCC dams. I: temperature and aging," Journal of Structural Engineering, vol. 126, no. 9, pp. 1053-1060, 2000.

[13] Y. Chen, C. Wang, S. Li, R. Wang, and J. He, "Simulation analysis of thermal stress of RCC dams using 3-D finite element relocating mesh method," Advances in Engineering Software, vol. 32, no. 9, pp. 677-682, 2001.

[14] J. Yang, Y. Hu, Z. Zuo, F. Jin, and Q. Li, “Thermal analysis of mass concrete embedded with double-layer staggered heterogeneous cooling water pipes," Applied Thermal Engineering, vol. 35, no. 1, pp. 145-156, 2012.

[15] R. Luna and Y. Wu, "Simulation of temperature and stress fields during RCC dam construction," Journal of Construction Engineering and Management, vol. 126, no. 5, pp. 381-388, 2000.

[16] A. Saetta, R. Scotta, and R. Vitaliani, "Stress analysis of concrete structures subjected to variable thermal loads," Journal of Structural Engineering, vol. 117, no. 2, pp. 446-457, 1991.

[17] Z. Zuo, Y. Hu, Y. Duan, and J. Yang, "Simulation of the temperature field in mass concrete with double layers of cooling pipes during construction," Journal of Tsinghua University, vol. 52, no. 2, pp. 186-228, 2012 (Chinese).

[18] J. Noorzaei, K. H. Bayagoob, W. A. Thanoon, and M. S. Jaafar, "Thermal and stress analysis of kinta RCC dam," Engineering Structures, vol. 28, no. 13, pp. 1795-1802, 2006.

[19] J. Noorzaei, K. H. Bayagoob, A. A. Abdulrazeg, M. S. Jaafar, and T. A. Mohammed, "Three dimensional nonlinear temperature and structural analysis of roller compacted concrete dam," Computer Modeling in Engineering and Sciences, vol. 47, no. 1, pp. 43-60, 2009.
[20] Z. Zuo, Y. Hu, Q. Li et al., "User-friendly thermal-stress coupled simulating platform of mass concrete," Chinese Journal of Computational Mechanics, vol. 30, no. S1, pp. 1-6, 2013 (Chinese).

[21] A. I. H. Malkawl, S. A. Mutasher, and T. J. Qiu, “Thermal-structural modeling and temperature control of roller compacted concrete gravity dam," Journal of Performance of Constructed Facilities, vol. 17, no. 4, pp. 177-187, 2003.

[22] Y. A. Cengel, Heat and Mass Transfer: A Practical Approach, McGraw-Hill, Boston, Mass, USA, 3rd edition, 2007.

[23] J. A. Palyvos, "A survey of wind convection coefficient correlations for building envelope energy systems' modeling," Applied Thermal Engineering, vol. 28, no. 8-9, pp. 801-808, 2008.

[24] Y. Lee, M.-S. Choi, S.-T. Yi, and J.-K. Kim, "Experimental study on the convective heat transfer coefficient of early-age concrete," Cement and Concrete Composites, vol. 31, no. 1, pp. 60-71, 2009.

[25] Y. Ballim, "A numerical model and associated calorimeter for predicting temperature profiles in mass concrete," Cement and Concrete Composites, vol. 26, no. 6, pp. 695-703, 2004.

[26] NIST. The NIST Reference on Constants, Units, and Uncertainty. 2011.

[27] ASHRAE, ASHRAE 2009 Fundamentals, Ashrae Handbook Series, Publications Traffic Administrator, Atlanta, Ga, USA, 2009.

[28] M. Iqbal, An Introduction to Solar Radiation, Academic Press, Toronto, Canada, 1983.

[29] F. Kasten and A. T. Young, "Revised optical air mass tables and approximation formula," Applied Optics, vol. 28, no. 22, pp. 4735-4738, 1989.

[30] D. Thevenard and K. Haddad, "Ground reflectivity in the context of building energy simulation," Energy and Buildings, vol. 38, no. 8, pp. 972-980, 2006.

[31] Y. Shiming, Heat Transfer, Higher Education Press, Beijing, China, 1998 (Chinese).

[32] W. S. Janna, Engineering Heat Transfer, CRC Press, New York, NY, USA, 2000.

[33] B.-F. Zhu, "Prediction of water temperature in reservoirs," Journal of Hydraulic Engineering, vol. 16, no. 2, pp. 12-21, 1985 (Chinese).

[34] S. C. Chapra, Surface Water-Quality Modeling, Waveland Press, Long Grove, Ill, USA, 1997.

[35] X. F. Zhang, S. Y. Li, Y. L. Li, Y. Ge, and H. Li, "Effect of superficial insulation on roller-compacted concrete dams in cold regions," Advances in Engineering Software, vol. 42, no. 11, pp. 939-943, 2011.

[36] USDOE, "Buried treasure: the environmental, economic, and employment benefits of geothermal energy," in Geothermal Technologies Program, Department of Energy, 2004.

[37] MSC Software Corporation, Theory and User Information, vol. A, MSC Software Corporation, Newport Beach, Calif, USA, 2012.

[38] B.-F. Zhu, "Compound exponential formula for variation of thermal and mechanical properties with age of concrete," Journal of Hydraulic Engineering, vol. 42, no. 1, pp. 1-7, 2011 (Chinese). 


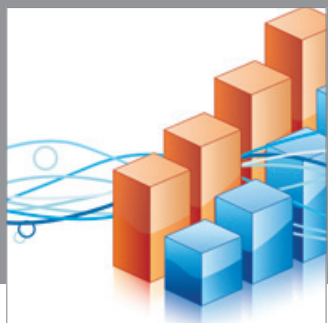

Advances in

Operations Research

mansans

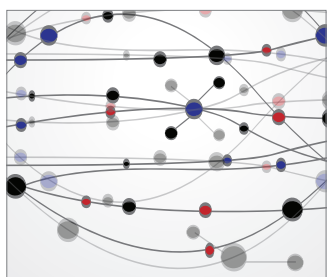

The Scientific World Journal
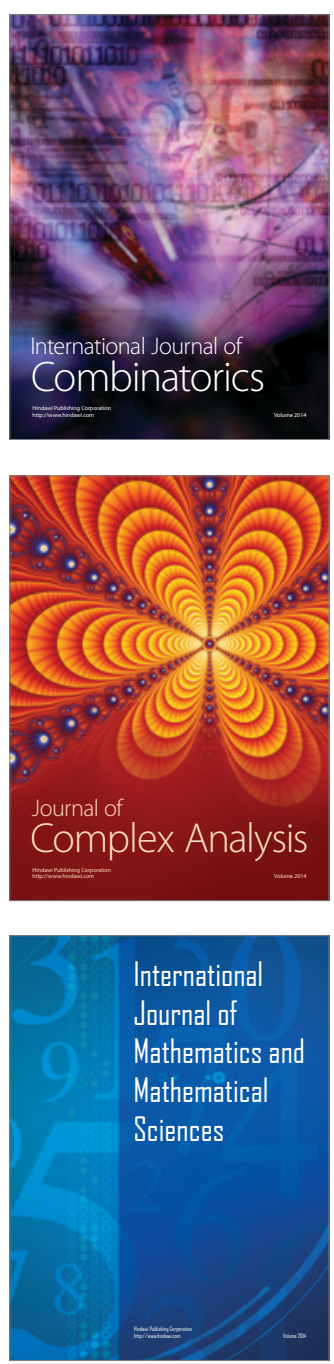
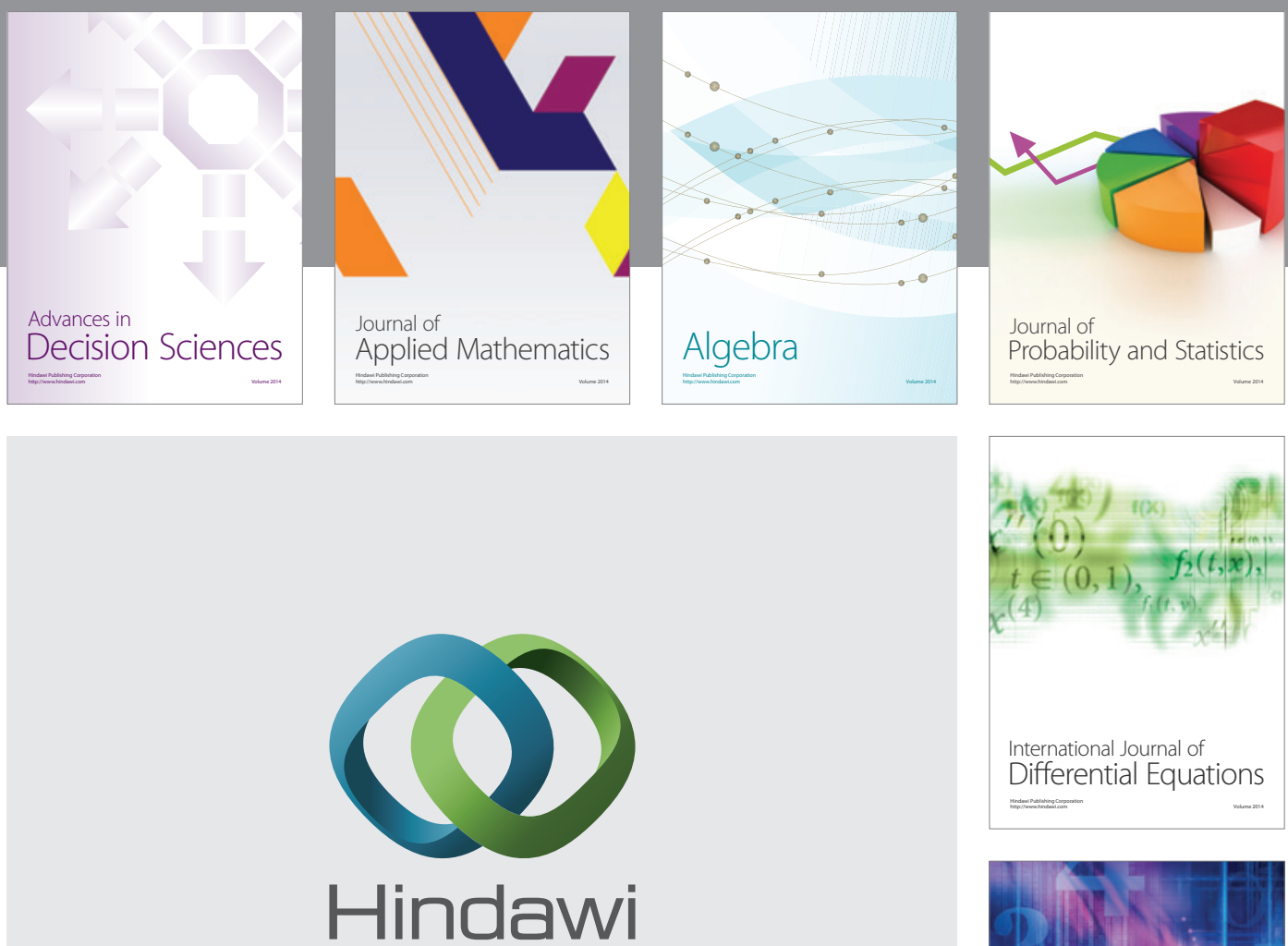

Submit your manuscripts at http://www.hindawi.com
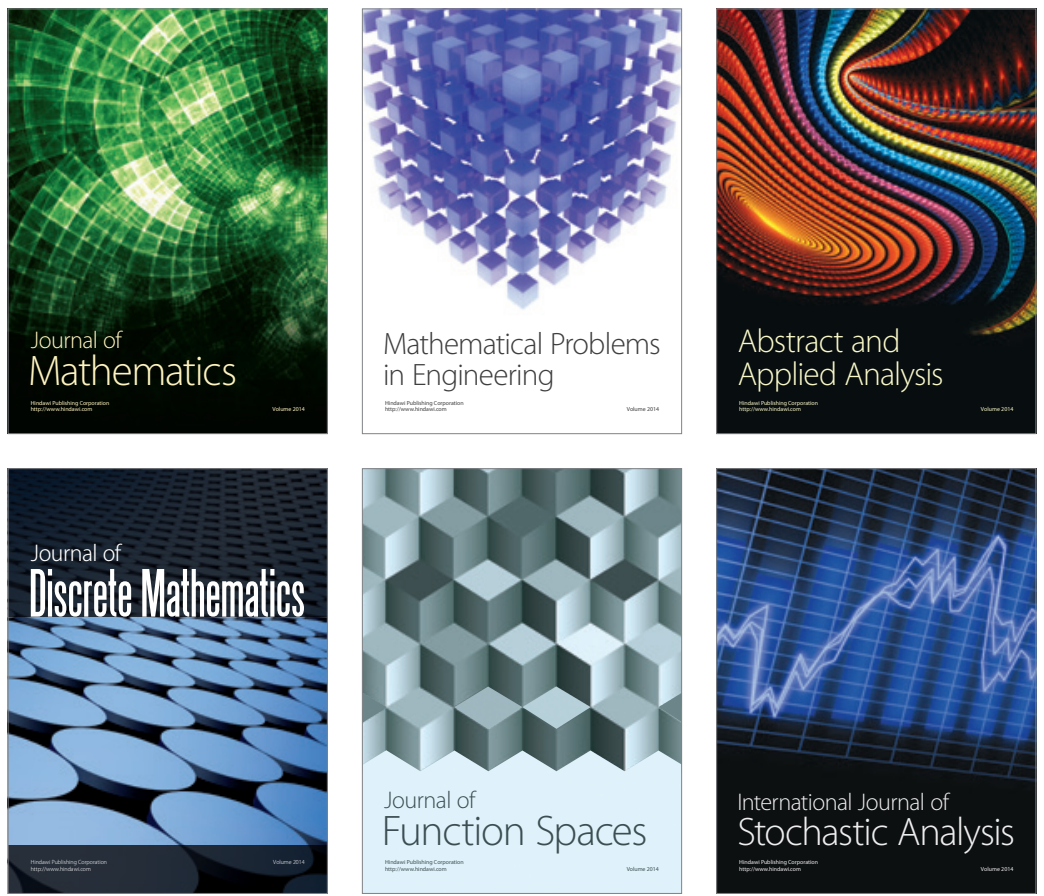

Journal of

Function Spaces

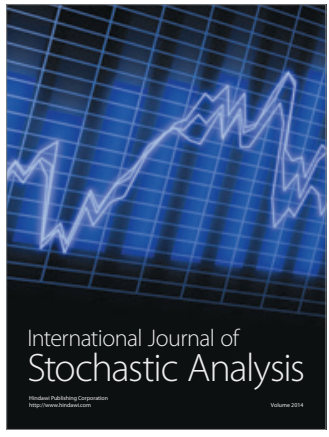

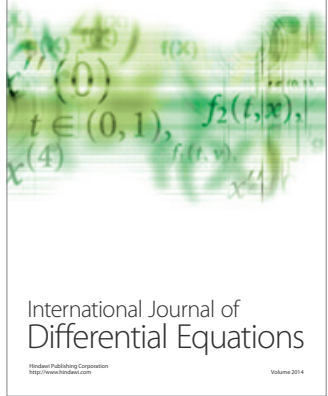
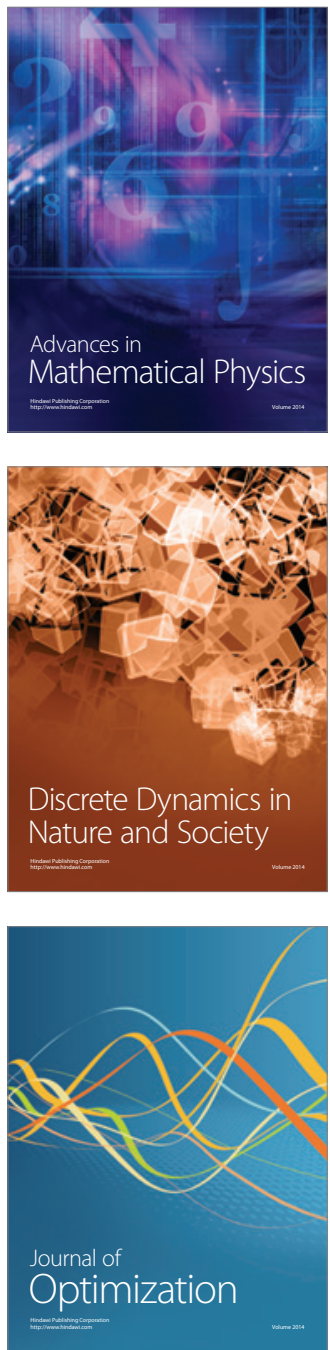